\title{
Transient Receptor Potential Melastatin 3 and Intracellular Calcium in Natural Killer Cells in Multiple Sclerosis
}

\author{
Laura Clarke1,2, Simon L. Broadley1,2, Thao Nguyen ${ }^{3,4}$, Samantha Johnston ${ }^{3,4}$, Natalie Eaton ${ }^{3,4}$, \\ Donald Staines $^{3,4}$, Sonya Marshall-Gradisnik ${ }^{3,4^{*}}$ \\ ${ }^{1}$ School of Medicine, Griffith University, Gold Coast, Australia \\ ${ }^{2}$ Department of Neurology, Gold Coast University Hospital, Gold Coast, Australia \\ ${ }^{3}$ The National Centre for Neuroimmunology and Emerging Diseases, Menzies Health Institute, Griffith University, Gold Coast, \\ Australia \\ ${ }^{4}$ School of Medical Science, Griffith University, Brisbane, Australia \\ Email: *ncned@griffith.edu.au
}

How to cite this paper: Clarke, L., Broadley, S.L., Nguyen, T., Johnston, S., Eaton, N., Staines, D. and Marshall-Gradisnik, S. (2018) Transient Receptor Potential Melastatin 3 and Intracellular Calcium in Natural Killer Cells in Multiple Sclerosis. International Journal of Clinical Medicine, 9, 541-565.

https://doi.org/10.4236/ijcm.2018.97047

Received: May 31, 2018

Accepted: July 7, 2018

Published: July 10, 2018

Copyright (c) 2018 by authors and Scientific Research Publishing Inc. This work is licensed under the Creative Commons Attribution International License (CC BY 4.0).

http://creativecommons.org/licenses/by/4.0/

\begin{abstract}
Background: Natural killer (NK) cell phenotypes have reported to be implicated in the pathomechanism of Multiple Sclerosis (MS). Several investigators have observed reduced peripheral numbers, reduced cytotoxic activity, and altered $\mathrm{CD} 56^{\mathrm{Dim}}$ and $\mathrm{CD} 56^{\text {Bright }} \mathrm{NK}$ cell phenotypes. This current project, for the first time, investigates the NK cell cytotoxicity, calcium mobilisation and transient receptor potential melastatin 3 (TRPM3) surface expression. Methods: NK cell cytotoxic activity and calcium signaling were examined in $\mathrm{CD} 56^{\mathrm{Dim}}$ and $\mathrm{CD} 56^{\text {Bright }} \mathrm{NK}$ cells before and after stimulation using Ionomycin, Pregnenolone sulphate, 2-Aminoethoxydiphenyl borate and Thapsigargin. Purified NK cells were labelled with antibodies to determine TRPM3, CD69 and CD107a surface expression using flow cytometry. Results: Twenty-two MS patients and 22 healthy controls were recruited for this project. Twelve of the 22 previously received Alemtuzumab (Lemtrada ${ }^{\circledR}$ ) and the remaining ten reported nil medication. We report TRPM3 was significantly increased in untreated MS patients compared with healthy controls and treated MS patients ( $p$-value 0.034). There was a significant decrease in CD69 surface expression on CD56 ${ }^{\text {Dim }} \mathrm{NK}$ cell phenotype for untreated MS patients ( $p$-value 0.031 ) and treated MS patients ( $p$-value 0.036 ). We report altered calcium mobilisation in CD56 ${ }^{\text {Bright }} \mathrm{NK}$ cells and to a lesser extent CD56 ${ }^{\text {Dim }} \mathrm{NK}$ cells between healthy controls, treated and untreated MS patients. Conclusion: This investigation suggests variations in TRPM3 expression and calcium mobilisation of NK cells may be implicated in the pathogenesis of MS. Further investigation is required to determine the mechanism by which alemtuzumab
\end{abstract}


alters calcium signaling in NK cells.

\section{Keywords}

Natural Killer Cells, Multiple Sclerosis, Calcium Signalling, Transient Receptor Potential Melastatin 3 Ion Channels

\section{Introduction}

Multiple Sclerosis (MS) is an inflammatory disease resulting in demyelination within the central nervous system (CNS). The aetiology of MS is multifactorial with studies implicating genetic, environmental, and epigenetic factors that ultimately appear to cause immune dysregulation in both the innate and adaptive immune systems [1] [2]. MS is the most common cause of neurological disability in young adults aged 20 - 45 years of age [3] and is predominately diagnosed in women [4]. Currently, there is no single, curative treatment for MS and therapies aim to suppress immune response in the CNS [3].

Natural killer (NK) cells have recently attracted significant attention for being implicated in the pathogenesis of MS [1] [5] [6] [7]. NK cells are a subset of lymphocytes in the innate immune system that are responsible for eliminating invading pathogens and tumour cells, as well as regulating $\mathrm{T}$ cell immunity [8]. There are two main subsets of NK cells defined by surface expression of CD56 and $\mathrm{CD} 16$ surface markers. $\mathrm{CD} 56^{\mathrm{Bright}} \mathrm{CD} 16^{\mathrm{Dim}} \mathrm{NK}$ cells have a high density surface expression and CD56 and are prominent in the production of cytokines. $\mathrm{CD} 56^{\text {Dim }} \mathrm{CD} 16^{\text {Bright }} \mathrm{NK}$ cells produce higher levels of lytic proteins; therefore they have the ability to mediate cytotoxicity on target cells [9]. Previous investigations have reported significant reductions in the number of circulating NK cells, reduction in NK cell cytotoxic activity, and a reduction in the production of pro-inflammatory cytokines in MS [5] [6] [10] [11] [12] [13]. A previous study has shown that changes to $\mathrm{CD} 56^{\text {Bright }} \mathrm{NK}$ cells enable autoreactive $\mathrm{T}$ cell survival that may contribute to lesion formation [14]. Furthermore, in one study NK cell functional activity was shown to diminish at the onset of clinical relapse, and normalised post relapse recovery [15].

Calcium $\left(\mathrm{Ca}^{2+}\right)$ mobilization and its regulation by ion channels are important in immune cell function [16]. In NK cells, polarisation of cytolytic granules and the release of lytic proteins are dependent on intracellular $\mathrm{Ca}^{2+}$ concentration [17], however the intracellular signalling mechanisms by which this is initiated and regulated requires further investigations.

The transient receptor potential (TRP) channel family comprise non-selective cation channels including $\mathrm{Ca}^{2+}$ permeable channels that play a role in the influx and transportation of intracellular $\mathrm{Ca}^{2+}$ [18]. There are six TRP subfamilies; TRPA (ankyrin), TRPC (canonical), TRPM (melastatin), TRPV (vanilloid), TRPML (mucolipin, and TRPP (polycystin) [19] [20]. TRP ion channels are widely expressed on tissues and cells that become activated in response to various 
stimuli in the cellular environment including pain, temperature, taste, pressure and vision [19]. TRPs have a role in store operated $\mathrm{Ca}^{2+}$ signalling in non-excitable cells including but not subjected to cells of the CNS [21]. TRP ion channels are expressed by multiple cell types throughout the body [18] including cells of the peripheral nervous system (PNS) and CNS [18] [22], and innate and adaptive immune system [16]. TRP ion channels have been implicated in neurological disease; therefore they pose as a potential therapeutic target [22]. TRP channels may have a role in the pathogenesis of MS [23] [24].

TRPM3 ion channels are transmembrane channels belonging to the melastatin subfamily [20]. There are seven isoforms identified in the human TRPM3 gene, including TRPM $3 \alpha 2$ which has been characterised as having a $\mathrm{Ca}^{2+}$ conducting pore and play a role in store-operated $\mathrm{Ca}^{2+}$ signaling [25] [26]. TRPM3 has been proposed to play roles in a variety of physiological and pathophysiological processes including but not subjected to noxious heat sensation [27]. TRPM3 is expressed in several tissues including the kidneys, eyes, sensory neurons of the dorsal root ganglia, pancreatic $\beta$ cells, and white matter of the CNS [26] [28]. More recently, it has been demonstrated that TRPM3 ion channels are expressed on the surface of both NK cells and B lymphocytes [29]. Previous research has documented TRPM2, TRPM4 and TRPM5 channel expression on lymphocyte subsets [30] [31]. However, there is limited literature on TRPM3 expression on NK cells as only two previous investigations using flow cytometry have reported TRPM3 [29] [32].

Whilst research to date suggests that NK cells may play a regulatory role in the pathogenesis of MS, the role of $\mathrm{Ca}^{2+}$ mobilisation in mediating NK cell cytotoxicity through $\mathrm{Ca}^{2+}$ specific receptors, such as TRPM3, has not been investigated. Moreover, the possible role of receptor/channel/ $\mathrm{Ca}^{2+}$ interaction in NK cells from MS patients has not been investigated. Therefore the aim of this study was to conduct a case-controlled study to investigate NK cell cytotoxic activity and intracellular $\mathrm{Ca}^{2+}$ mobilisation in healthy controls (HC) compared to untreated MS patients and patients administered with alemtuzumab. In addition, we examined TRPM3 surface expression as a possible mechanism for altered NK cell function in MS patients.

Additionally, Lemtrada ${ }^{\circledR}$ (alemtuzumab) is a humanised monoclonal antibody against cell surface protein CD52 [33]. CD52 is expressed primarily on T and B lymphocytes, but also minimally expressed on NK cells [34]. The exact function of CD52 is speculation, however, it is a targeted protein for antibody-dependent cytotoxicity induced by alemtuzumab therapy [33]. Alemtuzumab is a novel treatment for NK cell neoplasms [34] and proposed as a treatment for MS since the 1990s [35] [36]. A previous investigation suggested NK cells are a key component to alemtuzumab-dependent cytokine release and lymphocyte depletion by antibody-dependent cell mediated cytotoxicity [37]. As alemtuzumab is believed to activate NK cell cytotoxicity, for this reason, we also aimed to examine the effect of alemtuzumab therapy on NK cell cytotoxicity, TRPM3 expression and $\mathrm{Ca}^{2+}$ mobilisation. 


\section{Methods}

\subsection{Participants}

MS participants were recruited from specialist neurology outpatient clinics at a tertiary referral hospital, clinical trial outpatient clinics, and a previously established MS database three months prior to study commencement. This study was approved by the Griffith University Human Research Ethic Committee (MSC/18/13). MS patients were defined in accordance with the 2010 Revised McDonald diagnostic criteria [38]. Participants were recruited across all disease courses (clinically isolated syndrome, relapsing remitting, primary progressive, secondary progressive). Untreated MS participants were defined as those not currently on therapy for the treatment of MS, and were excluded if they had been on therapy for treatment of MS within the last six months. Participants in the treatment group were those previously treated with alemtuzumab (12 $\mathrm{mg} /$ dose), with inclusions for participants treated with both one course (5 days) or two courses ( 5 days +3 days, 12 months following initial therapy). Participants in both MS groups were further excluded if they were taking other immunomodulatory medications. HC were recruited between the ages of $18-65$ and upon clinical assessment were reported to be in good health. Participants were excluded if pregnant, breastfeeding, or had a history of smoking, another autoimmune disorder, psychosis, major depression, cardiovascular disease, thyroid disease or diabetes. Participants were excluded if they reported administration of medications that directly or indirectly effect TRPM3 activation and $\mathrm{Ca}^{2+}$ mobilisation.

Participants donated $80 \mathrm{~mL}$ of blood between 7:00 am and 11:00 am. Blood was collected into lithium-heparinised and ethylenediaminetetraacetic acid (EDTA) collection tubes. Peripheral blood mononuclear cells (PBMCs) and NK cells were isolated from $70 \mathrm{~mL}$ of whole blood while $10 \mathrm{~mL}$ was used for full blood analysis within six hours of blood collection. Pathology testing was performed to exclude concurrent inflammatory and chronic diseases and included full blood count, electrolytes, erythrocyte sedimentation rate (ESR), C-reactive protein, dehydroepiandrosterone, adrenocorticotropic hormone and cortisol. Clinical data collected included demographic details, age at onset, disease duration, number of relapses, disease course, prior medical history and exposures, expanded disability status scale (EDSS) and previous MS treatment.

\subsection{Peripheral Blood Mononuclear Cell and Natural Killer Cell Isolation}

PBMCs were isolated from whole blood via centrifugation over Ficoll density gradient medium (Ficoll GE Healthcare Bio-Sciences AB, Uppsala, Sweden). This was followed by immunomagnetic isolation of NK cells using EasySep NK cell enrichment kit (Stem Cell Technologies, Vancouver, BC, Canada) according to the manufacturer's instructions. Isolated NK cells were considered $89.5 \% \pm$ 3.64 for $\mathrm{HC}$ and $90.4 \% \pm 4.13$ for MS. 


\subsection{Drug Stimulation of Natural Killer Cells}

Isolated NK cells $\left(1 \times 10^{6}\right.$ cells $\left./ \mathrm{ml}\right)$ were stimulated by incubation for four hours at $37^{\circ} \mathrm{C}$ with $5 \% \mathrm{CO}_{2}$ in RPMI1640 supplemented with $10 \%$ fetal bovine serum (FBS) in the presence of the following stimulants at a final concentration of Ionomycin $(1 \mu \mathrm{M})$, Pregnenolone Sulphate (PregS) (1.35 uM), PregS $(1.35 \mu \mathrm{M})+$ 2-Aminoethoxydiphenyl borate (2-APB) $(50 \mu \mathrm{M})$, and PregS $(1.35 \mu \mathrm{M})+$ Thapsigargin (TG) $(1.42 \mu \mathrm{M}$,) 2-ABP $(50 \mu \mathrm{M})$, and $\mu \mathrm{MTG}(1.42 \mu \mathrm{M})$ (Bio-Techne, Tocris Bioscience, Sussex, UK, except Ionomycin purchased from Sigma, Mansfield, Australia). PregS reversibly activates TRPM3 leading to rapid influx in $\mathrm{Ca}^{2+}$ [39] while 2-APB acts to inhibit both IP3 receptors and TRP channels Ionomycin allows extracellular $\mathrm{Ca}^{2+}$ ions into the cytosol [32] while TG increases cytosolic $\mathrm{Ca}^{2+}$ through inhibition of the endoplasmic reticulum $\mathrm{Ca}^{2+}$ pump [40].

\subsection{TRPM3 Immunophenotyping in Natural Killer Cells}

TRPM3 expression on resting NK cells was identified as previously described [29] [32]. Isolated NK cells were incubated with primary fluorochrome labelled antibodies CD19-BV421, CD3-PerCP, CD56-BV421, CD16-APC Cy7 (purchased from Beckon Dickinson Bioscience, Miami, Florida, US) and TRPM3 primary antibody (purchased from Santa Cruz Biotechnology, Dallas, Texas, US) for 30 minutes at room temperature in the dark. Cells were washed and then incubated with TRPM3 secondary antibody (purchased from Santa Cruz Biotechnology, Dallas, Texas, US) for 30 minutes. NK cells were stimulated using the above protocol for four hours at $37^{\circ} \mathrm{C}$ with $5 \% \mathrm{CO}_{2}$ in RPMI-1640 (Invitrogen Life Technologies, Carlsbad, CA, USA) supplemented with 10\% fetal bovine serum (FBS) (Invitrogen Life Technologies, Carlsbad, CA, USA).

Cells were stained with CD69, CD107a and TRPM3 primary antibody for 30 minutes to determine CD69, CD107a and TRPM3 receptors expression on CD56 ${ }^{\text {Dim }}$ and CD56 ${ }^{\text {Bright }} \mathrm{NK}$ cell phenotypes. TruCount counting beads (BD Bioscience, San Jose, CA, USA) were used to calculate NK cell concentration as well as absolute cell counts and was determined using the manufacturer's instructions outline in the below formula. Cells were washed and resuspended in $200 \mu \mathrm{l}$ of staining buffer (BD Bioscience, San Jose, CA, USA) and acquired using LSRFortessa X-20 (BD Bioscience, San Jose, CA, USA). Isotype controls were used to determine appropriate gating as previously described [32]. 20,000 events were recorded for each sample.

$$
\begin{aligned}
& \frac{\text { number of events in cell region }}{\text { number of events in bead region }} \times \frac{\text { number of beads } / \text { test }}{\text { test volume }} \times \text { dilution factor } \\
& =\text { cell population concentration }
\end{aligned}
$$

\subsection{Cytoplasmic Calcium in Natural Killer Cells}

$\mathrm{Ca}^{2+}$ flux was performed as previously described [29] [32]. $\mathrm{Ca}^{2+}$ signalling was measured in the presence of the following stimulants at a final concentration of $1 \mu \mathrm{M}$ Ionomycin, $1.35 \mu \mathrm{M}$ PregS, $1.35 \mu \mathrm{M}$ PregS + $50 \mu \mathrm{M}$ 2-APB, $1.35 \mu \mathrm{M}$ PregS 
$+1.42 \mu \mathrm{M}$ TG, $50 \mu \mathrm{M}$ 2-ABP alone, and $1.42 \mu \mathrm{M}$ TG alone. Assessment of $\mathrm{Ca}^{2+}$ influx dependent on TRPM3 was determined using PregS. CD56 and CD16 antibodies were used to determine NK cell phenotypes during flow cytometry. Cells were stimulated for five minutes and recorded in real time on flow cytometry.

\subsection{Natural Killer Cell Cytotoxicity}

Assessment of NK cell cytotoxic activity was performed as previously described [41]. Following NK cell isolation and labeling with 0.4\% Paul Karl Horan (PKH-26) (Sigma-Aldrich, St Louis, MO, USA), NK cells were stimulated in the presence of the following drugs at a final concentration of $1 \mu \mathrm{M}$ Ionomycin, 1.35 $\mu \mathrm{M}$ PregS, $1.35 \mu \mathrm{M}$ PregS + $50 \mu \mathrm{M}$ 2-APB, $1.35 \mu \mathrm{M}$ PregS + $1.42 \mu \mathrm{M}$ TG. Under stimulated conditions at effector to target ratio (E: T) of 1:1 was utilised. A baseline measurement of NK cell cytotoxic activity was also performed using E: T of 25:1, 12:1, 6:1 and 1:1. Cells were washed and plated with K562 cells. Cells were incubated for four hours at $37^{\circ} \mathrm{C}$ with $5 \% \mathrm{CO}_{2}$ in RPMI-1640 supplemented with $10 \%$ FBS. Post incubation, cells were stained with Annexin V (2.5 $\mu \mathrm{l} /$ test $)$ and 7 -amino-acetinomycin (7-AAD) $(2.5 \mu \mathrm{l} /$ test $)$ for determination of K562 viability [42]. K562 cell viability was then determined into 4 stages; live/viable K562 cells (AnnexinV-/7AAD-), K562 cells undergoing early stage apoptosis (Annexin $\mathrm{V}+/ 7 \mathrm{AAD}-$ ), late stage apoptosis (AnnexinV+/7AAD+), and dead K562 cells (AnnexinV-/7AAD+). K562 cell death was then calculated as previously described [42]. Flow cytometry was used to determine target cell apoptosis recording 20,000 events for each sample.

\subsection{Data and Statistical Analysis}

Data was exported from FacsDiva v8.1 and analysed using Flowjo software v10. Data was quantified, and statistical analysis was performed using SPSS 22.2 software. Shapiro-Wilk testing was performed for normality and Mann-Whitney $\mathrm{U}$ test was used to determine the relationship between healthy control and the MS group under each stimulant/condition with respect to TRPM3 expression, CD69 and CD107a surface expression on NK cell subsets, calcium signalling, area under the curve (AUC), and NK cell cytotoxic activity. Kruskal-Wallis test was then used to determine the relationship between healthy controls, the untreated MS group and MS group treated with alemtuzumab for the aforementioned measures. Statistical significance was set at $<0.05$. Demographic and patient data outputs are reported as mean \pm SEM unless otherwise stated. ANOVA testing was performed on sociodemographic data and pathology results.

\section{Results}

\subsection{Participants}

A total of 44 participants were included; $22 \mathrm{HC}, 12$ untreated MS, and $10 \mathrm{MS}$ patients treated with alemtuzumab. The sociodemographic and pathology data for 
participants is summarised in Table 1 and Table 2 (Data not shown is summarised in Supplementary Table 1). There were no significant differences in age or

Table 1. Demographic data.

\begin{tabular}{cccc}
\hline & HC & MS-Treated & MS-Untreated \\
\hline N & 22 & 22 & 12 \\
Age (years) & $39.4 \pm 12.5$ & $41.1 \pm 15.2$ & $46.5 \pm 17.0$ \\
Female n (\%) & $6(73)$ & $17(77)$ & $8(67)$ \\
Male n (\%) & $16(27)$ & $5(23)$ & $4(33)$ \\
\hline
\end{tabular}

Data shown indicates mean \pm standard deviation $(\mathrm{SD})$. Gender results represented as number and percentage. Abbreviations: HC, healthy control; MS, multiple sclerosis.

Table 2. Pathology results.

\begin{tabular}{|c|c|c|c|c|c|c|c|c|c|}
\hline & \multicolumn{2}{|c|}{ Healthy control } & \multicolumn{3}{|c|}{ MS-Untreated } & \multicolumn{3}{|c|}{ MS-Treated } & \multirow{2}{*}{$\begin{array}{c}\text { MS Untreated } \\
\text { vs Treated } \\
p \text {-value }\end{array}$} \\
\hline & Mean & SD & Mean & SD & $p$-value vs $\mathrm{HC}$ & Mean & SD & $p$-value vs $\mathrm{HC}$ & \\
\hline Cholesterol mmolL & 4.8 & 0.8 & 4.8 & 1.0 & 1 & 4.9 & 0.7 & 1 & 1 \\
\hline Haemoglobin gL & 137.8 & 11.9 & 130.8 & 34.3 & 1 & 134.4 & 8.1 & 1 & 1 \\
\hline $\mathrm{WBC} \times 10^{9} / \mathrm{L}$ & 5.9 & 1.3 & 6.7 & 1.4 & 0.27 & 4.8 & 1.2 & 0.079 & 0.003 \\
\hline Platelet $\times 10^{9} / \mathrm{L}$ & 263.7 & 71.2 & 278.3 & 37.2 & 1 & 243.0 & 43.4 & 1 & 0.49 \\
\hline Haematocrit & 0.41 & 0.03 & 0.42 & 0.04 & 1 & 0.41 & 0.02 & 1 & 0.889 \\
\hline $\mathrm{RBC} \times 10^{12} / \mathrm{L}$ & 4.65 & 0.39 & 4.68 & 0.53 & 1 & 4.59 & 0.35 & 1 & 1 \\
\hline MCV fL & 88.8 & 4.4 & 90.0 & 2.0 & 1 & 88.1 & 4.0 & 1 & 0.744 \\
\hline Neutrophils $\times 10^{9} / \mathrm{L}$ & 3.50 & 0.89 & 4.29 & 1.36 & 0.150 & 3.42 & 1.12 & 1 & 0.208 \\
\hline Lymphocyte $\times 10^{9} / \mathrm{L}$ & 1.90 & 0.63 & 1.86 & 0.41 & 1 & 0.88 & 0.29 & $<0.001$ & $<0.001$ \\
\hline Monocyte $\times 10^{9} / \mathrm{L}$ & 0.33 & 0.10 & 0.39 & 0.13 & 0.348 & 0.29 & 0.09 & 0.992 & 0.095 \\
\hline Eosinophils $\times 10^{9} / \mathrm{L}$ & 0.15 & 0.08 & 0.16 & 0.09 & 1 & 0.16 & 0.10 & 1 & 1 \\
\hline Basophil $\times 10^{9} / \mathrm{L}$ & 0.03 & 0.02 & 0.04 & 0.02 & 0.916 & 0.02 & 0.01 & 0.577 & 0.140 \\
\hline ESR mmHr & 13.5 & 10.2 & 19.6 & 14.6 & 0.409 & 11.6 & 8.4 & 1 & 0.314 \\
\hline DHEA Sulphate umolL & 4.0 & 2.1 & 4.2 & 3.9 & 1 & 4.3 & 4.2 & 1 & 1 \\
\hline ACTH ngL & 16.8 & 7.2 & 16.3 & 9.7 & 1 & 19.4 & 12.6 & 1 & 1 \\
\hline Cortisol nmolL & 365.8 & 134.9 & 295.3 & 89.7 & 0.429 & 388.8 & 162.8 & 1 & 0.314 \\
\hline Hs CRP & 2.04 & 2.21 & 3.33 & 4.92 & 0.733 & 1.57 & 1.12 & 1 & 0.550 \\
\hline sodium & 136.3 & 2.2 & 136.7 & 3.3 & 1 & 137.4 & 2.4 & 0.772 & 0.803 \\
\hline Potassium & 4.1 & 0.4 & 4.2 & 0.4 & 1 & 4.0 & 0.2 & 0.803 & 0.756 \\
\hline chloride & 102.5 & 2.0 & 100.8 & 3.0 & 0.134 & 103.2 & 2.5 & 1 & 0.068 \\
\hline Bicarbonate & 26.4 & 2.0 & 28.0 & 1.8 & 0.080 & 26.5 & 2.1 & 1 & 0.255 \\
\hline AnionGap & 7.5 & 1.9 & 7.9 & 1.6 & 1 & 7.8 & 1.8 & 1 & 1 \\
\hline
\end{tabular}

Data shown indicates mean, $\mathrm{SD}$ and $p$-values. Significant p-values highlighted in bold text. Abbreviations: MS: Multiple sclerosis, WBC: White blood cell, RBC: Red blood cell, MCV: Mean Corpuscular Volume, ESR: Erythrocyte sedimentation rate, CRP: C-reactive protein, DHEA: Dehydroepiandrosterone, ACTH: Adrenocorticotropic hormone. 
gender between groups. There was no significant difference between the number of relapses, disease course, and EDSS between MS groups. The age of onset in the treated MS group was significantly lower than the age of onset in the untreated MS group ( $p$-value 0.004). There was a significant difference in the white cell count (WCC) between untreated and treated MS patients (mean untreated $6.7 \times 10^{9} / \mathrm{L}$ vs mean treated $4.8 \times 10^{9} / \mathrm{L}, p$-value 0.003$)$. There was a significant reduction in lymphocyte count of the treated MS group compared to HC (mean HC $1.9 \times 10^{9} / \mathrm{L}$ vs mean treated $0.88 \times 10^{9} / \mathrm{L}$, $p$-value $<0.001$ ), and a significant reduction in lymphocyte count in the treated MS group compared to untreated MS group (mean untreated $1.86 \times 10^{9} / \mathrm{L}$ vs mean treated $0.88 \times 10^{9} / \mathrm{L}$, $p$-value $<0.001)$. There was no significant difference in lymphocyte count between HC and the untreated MS group.

\subsection{Natural Killer Cell Cytotoxicity}

There was no significant difference in NK cell cytotoxic activity in HC compared with the MS group, nor was there any difference in NK cell cytotoxic activity between HC and MS subgroups, at any E:T (Data not shown). There was no significant difference seen with stimulation. A patient with Primary Progressive MS (PPMS) was removed from analysis as a possible outlier. With the removal of this individual, no significant difference in NK cell cytotoxicity remained.

\subsection{TRPM3 Expression and Activation Markers on Natural Killer Cells}

TRPM3 expression was significantly increased in CD56 ${ }^{\mathrm{Dim}} \mathrm{NK}$ cells in the untreated MS group compared with HC when under the stimulation of PregS ( $p$-value 0.034) (Figure 1). Interestingly, in CD56 ${ }^{\mathrm{Dim}} \mathrm{NK}$ cells the treated MS group demonstrated no significant difference in TRPM3 expression than the HC group, suggesting TRPM3 may have reverted to normal expression with alemtuzumab treatment in these cells. A significant increase in TRPM3 expression was observed in $\mathrm{CD} 56^{\text {Bright }} \mathrm{NK}$ cells of untreated MS patients when compared with $\mathrm{HC}$ and treated MS patients (Figure 1(b)).

When unstimulated, CD69 expression was significantly lower on CD56 ${ }^{\text {Dim }} \mathrm{NK}$ Cells of the untreated MS group when compared with both HC ( $p$-value 0.031) and treated MS group ( $p$-value 0.036) (Figure 2(a)).

There was no significant difference in CD69 expression in the CD56 ${ }^{\text {Bright }}$ cell population prior to drug stimulation (Figure 3(a)). Under stimulation with 2-ABP, there was a significant increase in CD56 ${ }^{\text {Bright }} \mathrm{NK}$ cells expressing CD69 in the untreated MS group compared with HC ( $p$-value 0.015) (Figure 3(a)). There was an increase in CD56 ${ }^{\text {Bright }} \mathrm{NK}$ cells expressing CD69 in the untreated MS group compared with the treated MS group that approached, but did not achieve significance ( $p$-value 0.081). Under stimulation with PregS alone, PregS + 2-ABP and 2-ABP alone, CD69 expression on CD56 ${ }^{\mathrm{Dim}} \mathrm{NK}$ cells was significantly higher in the treated MS group compared with the untreated MS group. Under these 


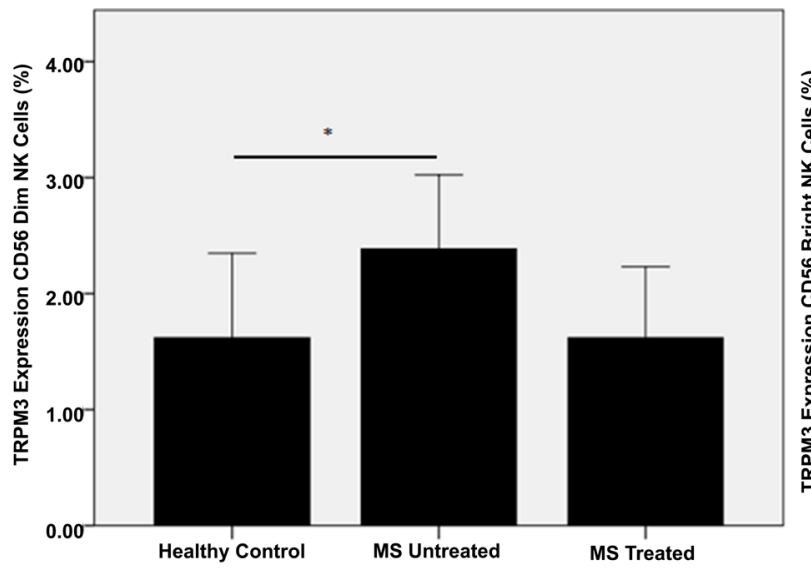

(a)

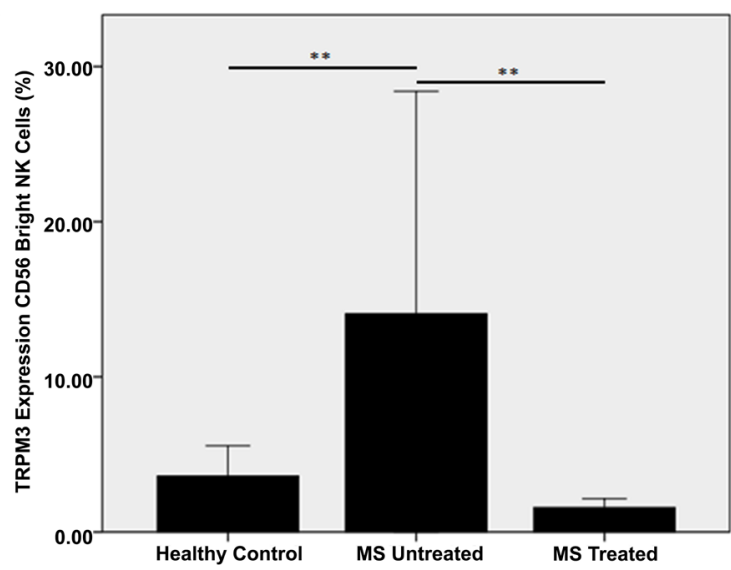

(b)

Figure 1. TRPM3 expression under Pregenolone Sulphate. (a) illustrates TRPM3 expression on CD56 ${ }^{\text {Dim }}$ NK cells; (b) illustrates TRPM3 expression on CD56 ${ }^{\text {Bright }} \mathrm{NK}$ cells. Data are represented as mean \pm SEM. Asterisks $\left({ }^{*}\right)$ represent statistical significance at $p$ value $<0.05$. Abbreviations: MS: Multiple sclerosis, NK: natural killer, TRPM3: Transient receptor potential melatastin.

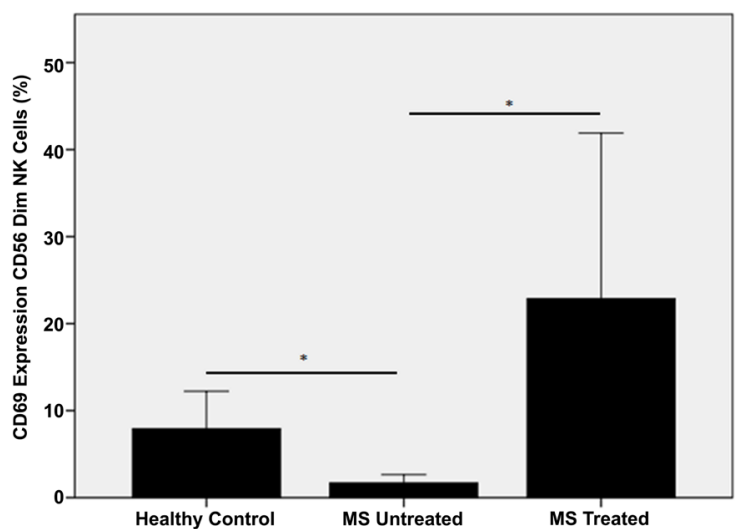

(a)

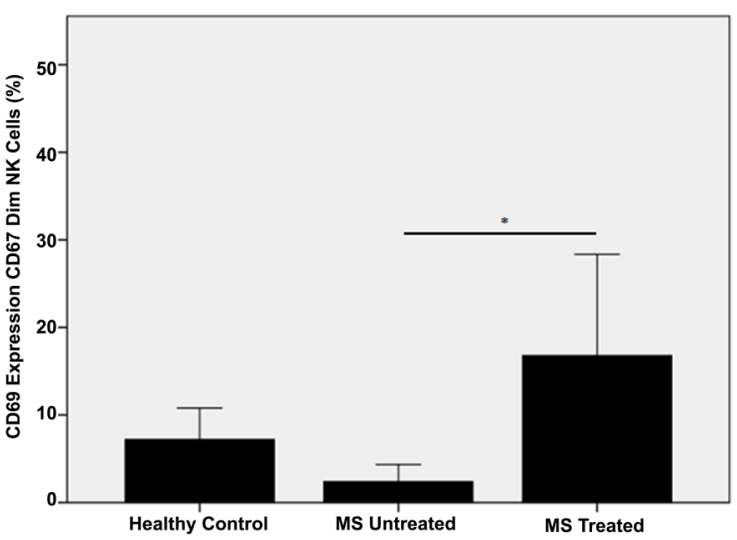

(c)

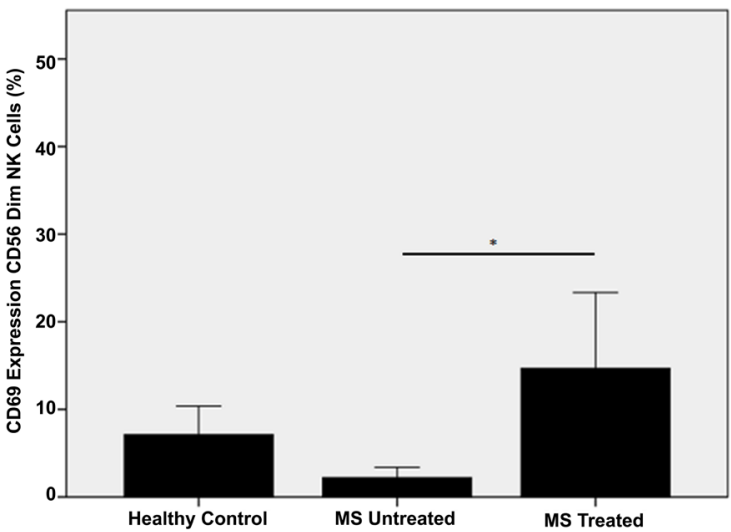

(b)

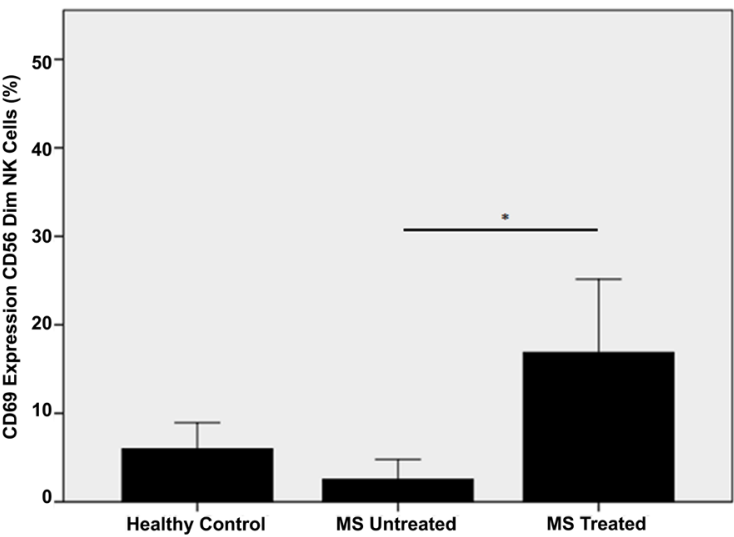

(d)

Figure 2. Expression activation markers on CD56 ${ }^{\text {Dim }}$ NK cells. (a) CD56 ${ }^{\text {Dim }}$ NK Cells expressing CD69-US; (b) CD56 $^{\text {Dim }}$ NK Cells expressing CD69-treated 2-ABP; (c) CD56 ${ }^{\text {Dim }}$ NK Cells expressing CD69-PregS; (d) CD56 ${ }^{\text {Dim }}$ NK Cells expressing CD69-PregS +2 -ABP. Data are represented as mean \pm SEM. Asterisks $\left.{ }^{*}\right)$ represent statistical significance at $p$ value < 0.05. Abbreviations: PregS: Pregnenolone sulphate, TG: Thapsigargin, 2-ABP: 2-Aminoethoxydiphenyl borate, MS: Multiple sclerosis, NK: natural killer. 


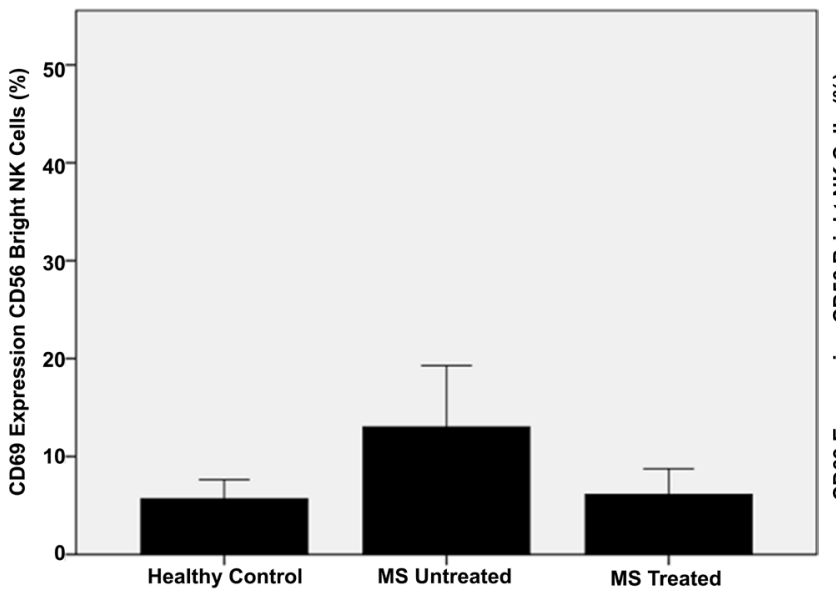

(a)

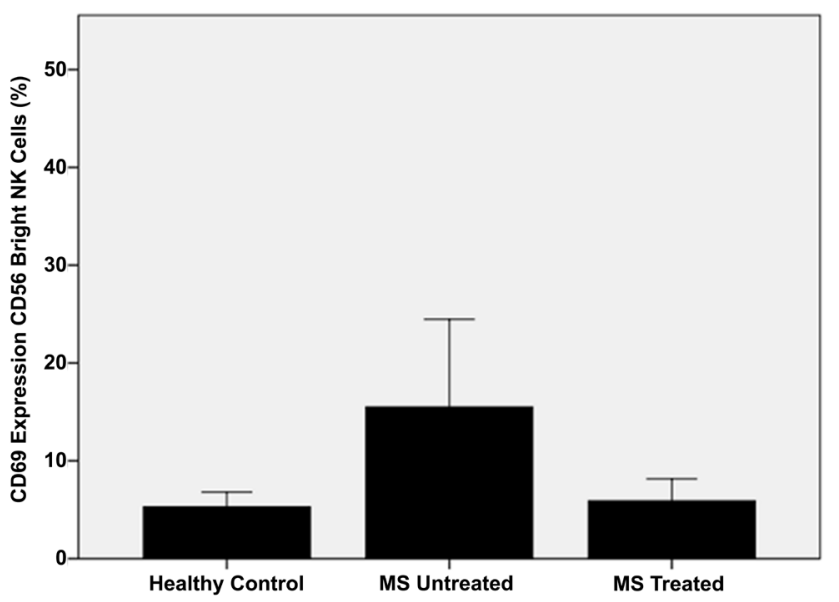

(c)

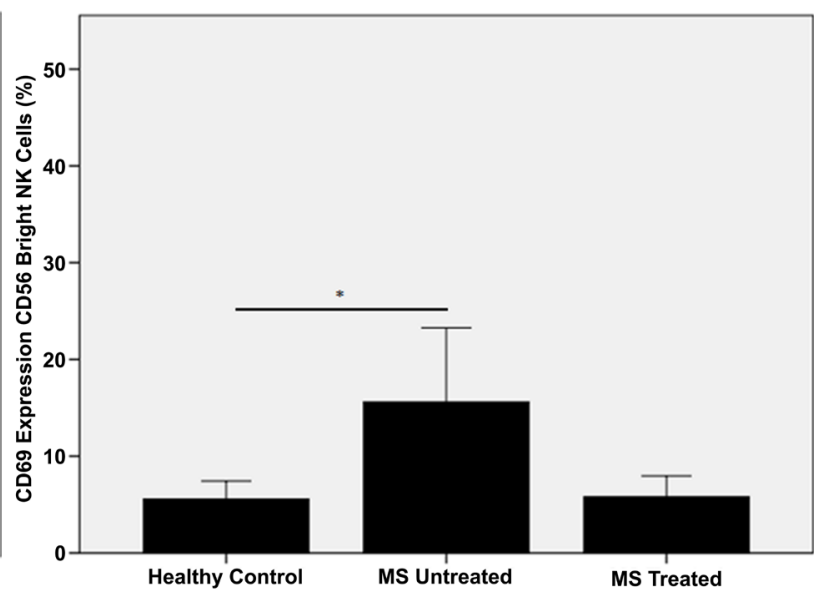

(b)

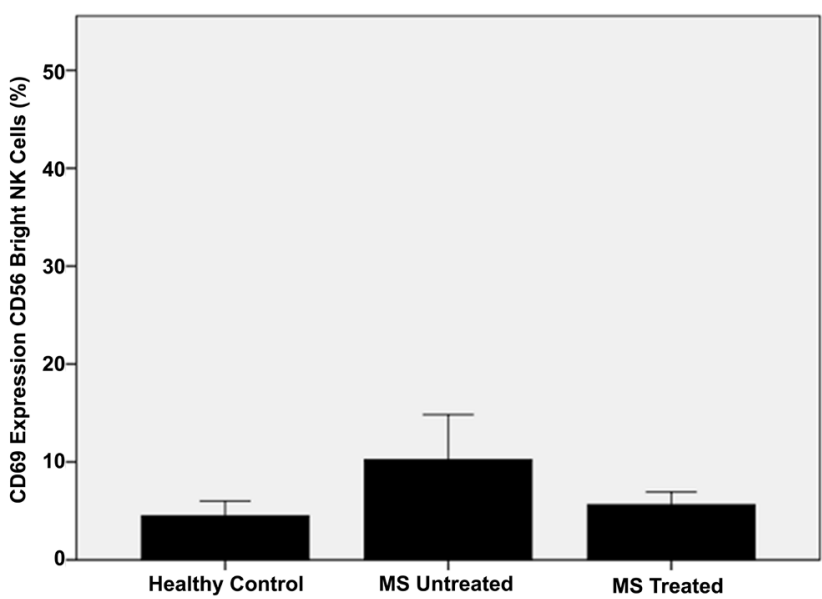

(d)

Figure 3. Expression activation markers on CD56 $6^{\text {Bright }}$ NK cells. (a) CD56 $6^{\text {Bright }}$ NK Cells expressing CD69-US; (b) CD56 ${ }^{\text {Bright }}$ NK Cells expressing CD69-treated 2-ABP; (c) CD56 ${ }^{\text {Bright }}$ NK Cells expressing CD69-PregS; (d) CD56 ${ }^{\text {Bright }}$ NK Cells expressing CD69-PregS +2 -ABP. Data are represented as mean \pm SEM $\left.{ }^{*}\right)$ represent statistical significance at $p$ value $<0.05$. Abbreviations: US: Unstimulated, PregS: Pregnenolone sulphate, 2-ABP: 2-Aminoethoxydiphenyl borate, MS: Multiple sclerosiss, NK: natural killer.

conditions, there was no significant difference between $\mathrm{HC}$ and the untreated MS group (Figure 2).

There was a significant increase in CD107a expression on CD56 $6^{\text {Bright }} \mathrm{NK}$ cells in untreated MS patients compared with HC and treated MS patients (Figure 4(a)). There was no significant difference in CD107a expression on CD $56^{\mathrm{Dim}} \mathrm{NK}$ cells (Figure 4(b)).

\subsection{Intracellular Calcium Mobilisation}

The There was no significant difference in $\mathrm{Ca}^{2+}$ signalling between subgroups with no stimulation. However, in the CD56 ${ }^{\text {Bright }} \mathrm{NK}$ cell population there was a trend towards increased AUC in the treated MS group compared with HC ( $p$ value 0.052 ) (Figure $5(\mathrm{~g})$ ).

The CD56 $6^{\text {Bright }} \mathrm{NK}$ cell population showed significantly increased AUC in the treated MS group compared with HC after 2-ABP (Figure 5(a)) and PregS + 


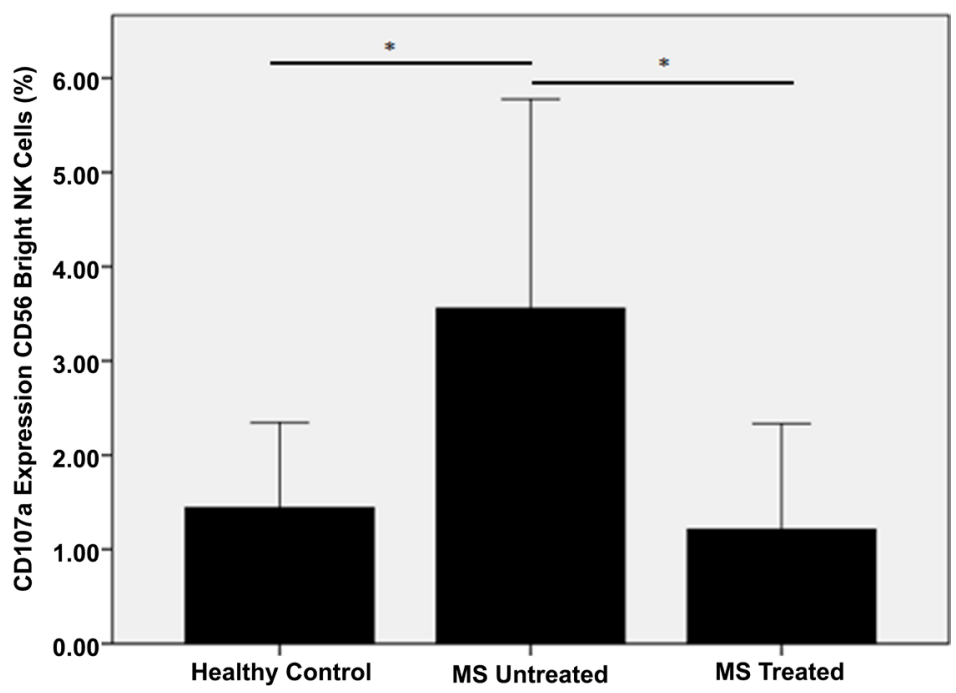

(a)

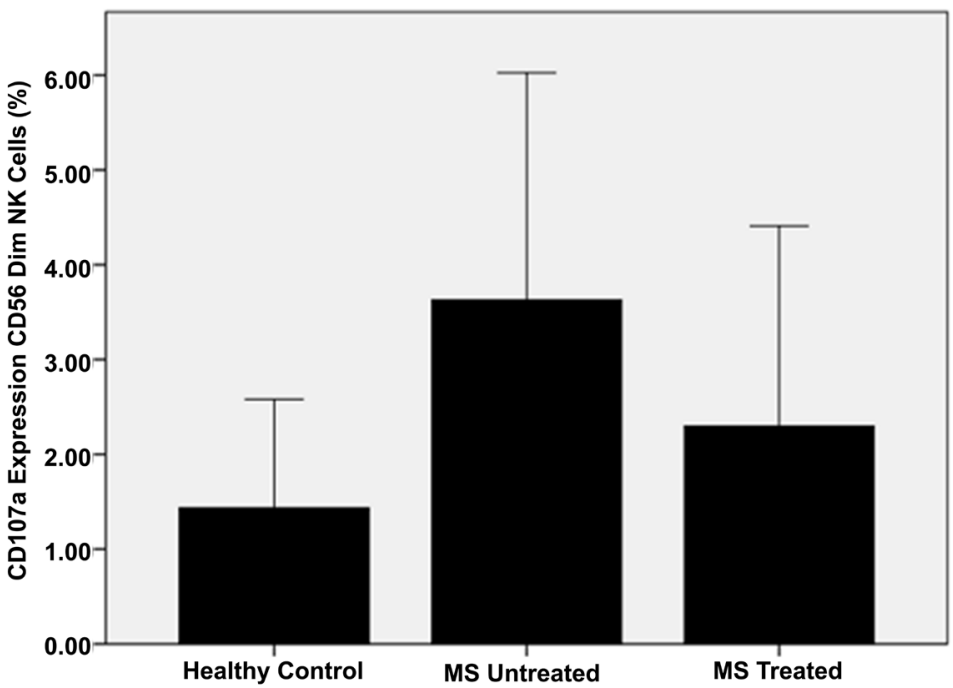

(b)

Figure 4. CD107a expression on NK cells. (a) CD107a expression on CD56 ${ }^{\text {Bright }}$ NK cells; (b) CD107a expression on CD56 ${ }^{\text {Dim }} \mathrm{NK}$ cells. Data are represented as mean \pm SEM. * represent statistical significance at $p$ value $<0.05$. Abbreviations: NK, natural killer; MS, multiple sclerosis.

2-ABP (Figure 5(d)) treatment ( $p$ values 0.019 and 0.004 respectively). Under treatment with PregS alone, there was a trend towards increased AUC in the treated MS group compared with HC that did not reach significance ( $p$ value 0.071) (Figure 5(c)). The CD56 ${ }^{\text {Bright }}$ NK cell population showed significantly increased AUC in the treated MS group compared with the untreated MS group under all treatment conditions except PregS + 2-ABP (Figure 5(d)).

The CD56 ${ }^{\text {Dim }}$ NK cell population showed significant increase in AUC in both the untreated and treated MS groups compared with $\mathrm{HC}$ when under treatment with PregS + 2-ABP (Figure 6(a)). There was no significant increase in AUC between subgroups under PregS or 2-ABP alone. The CD56 ${ }^{\mathrm{Dim}} \mathrm{NK}$ cell population 


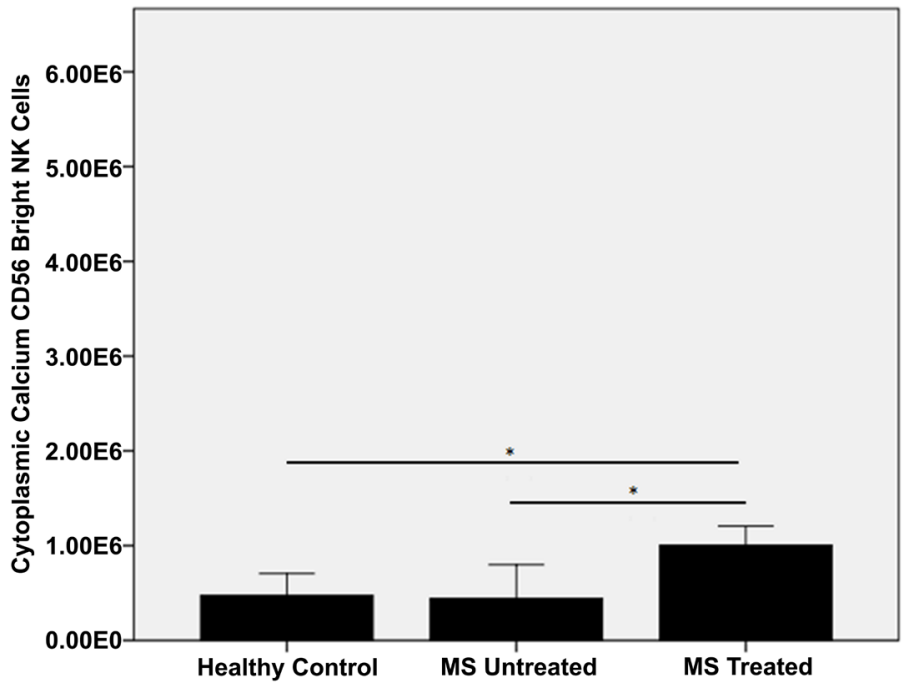

(a)

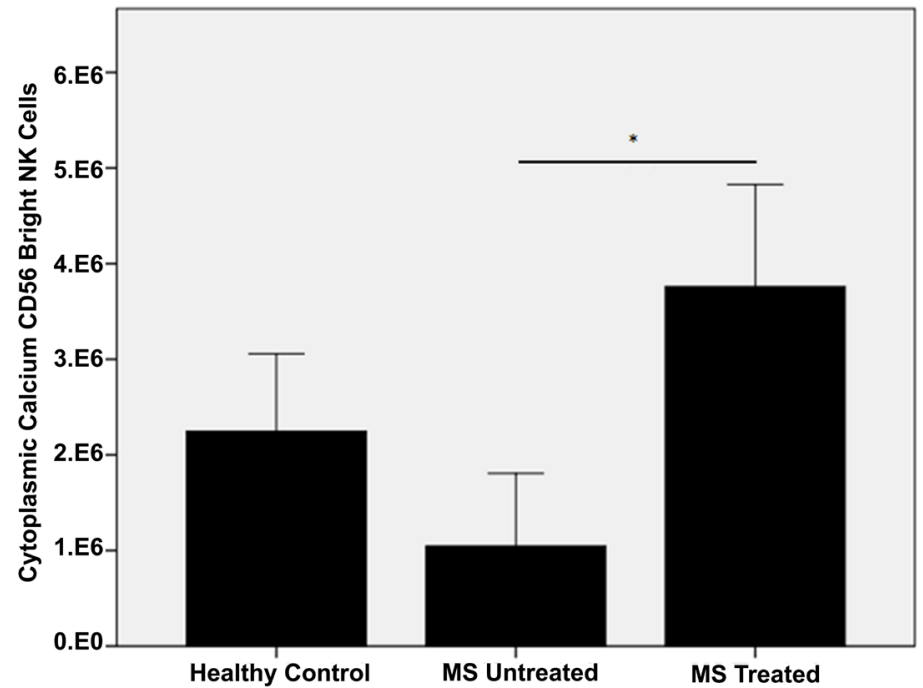

(b)

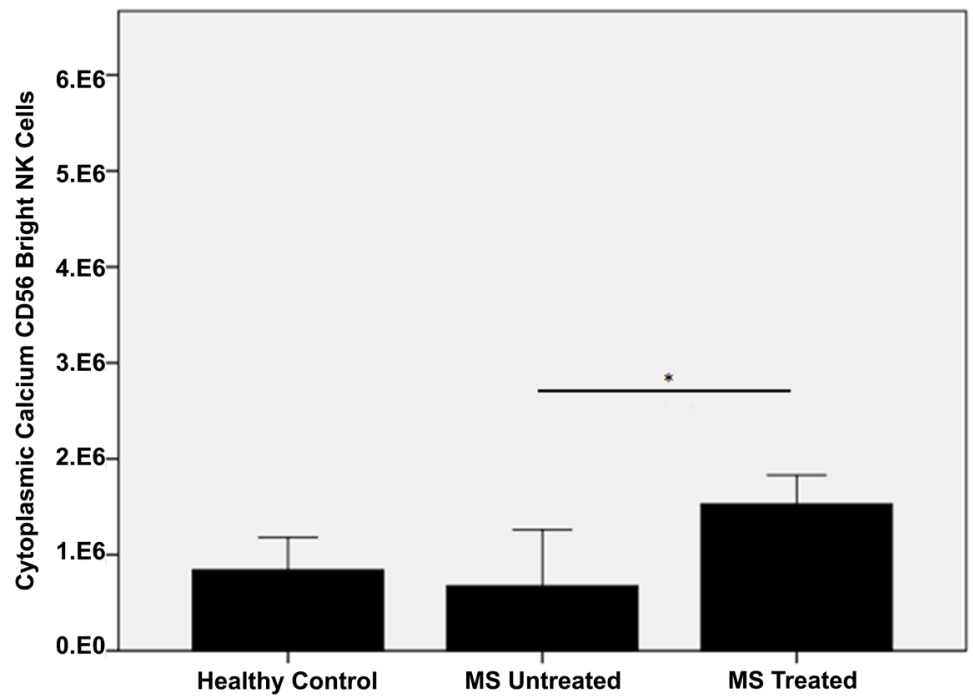

(c) 


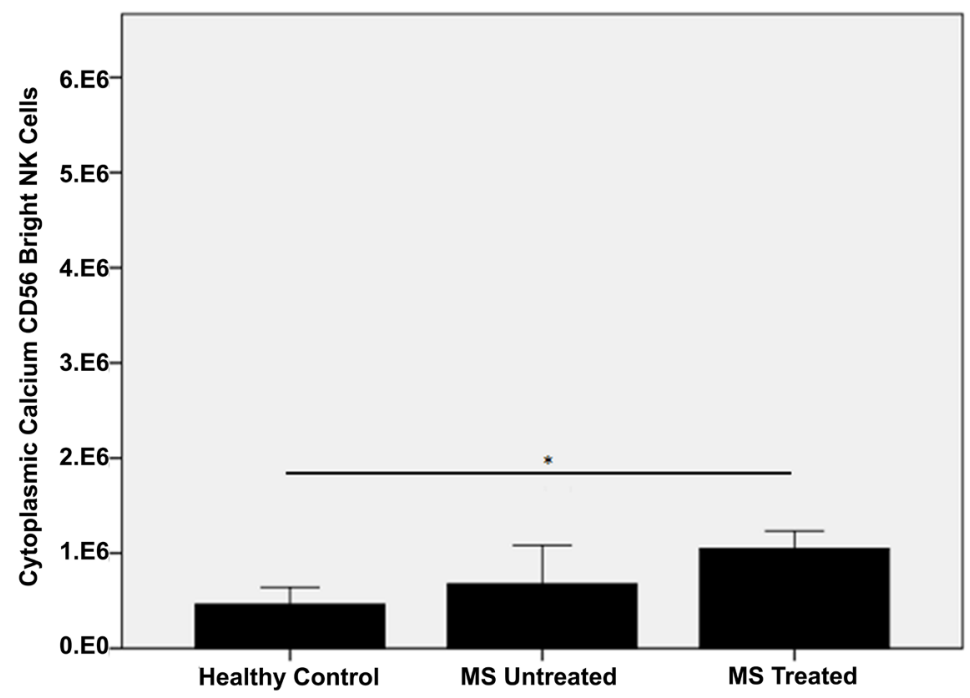

(d)

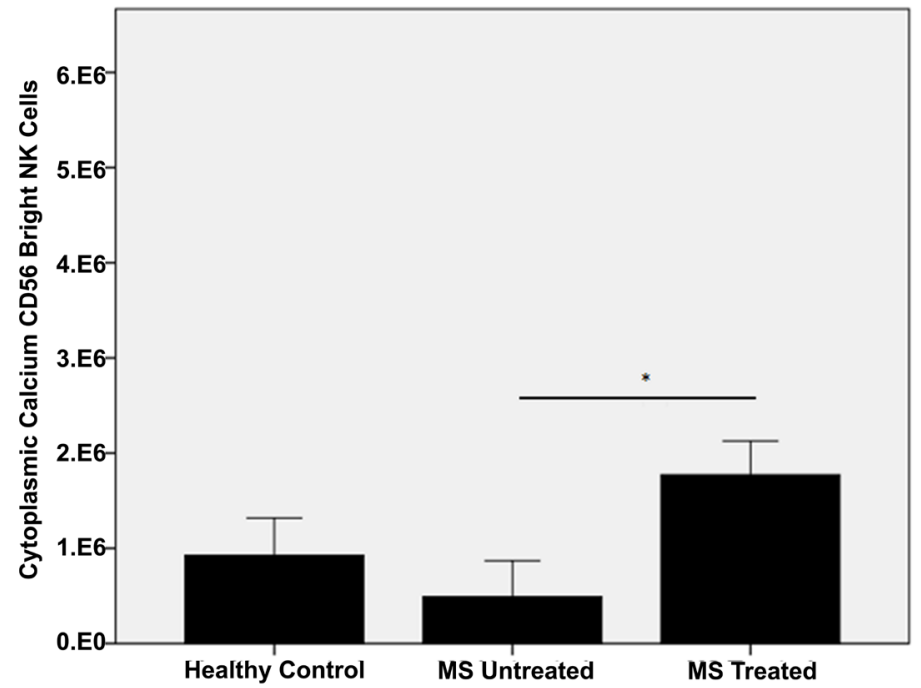

(e)

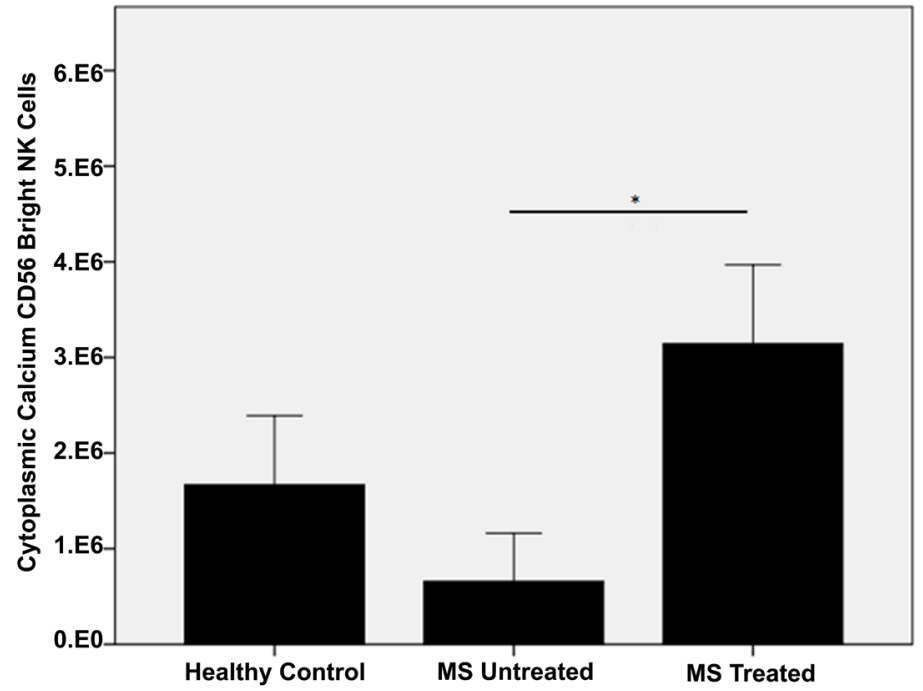

(f) 


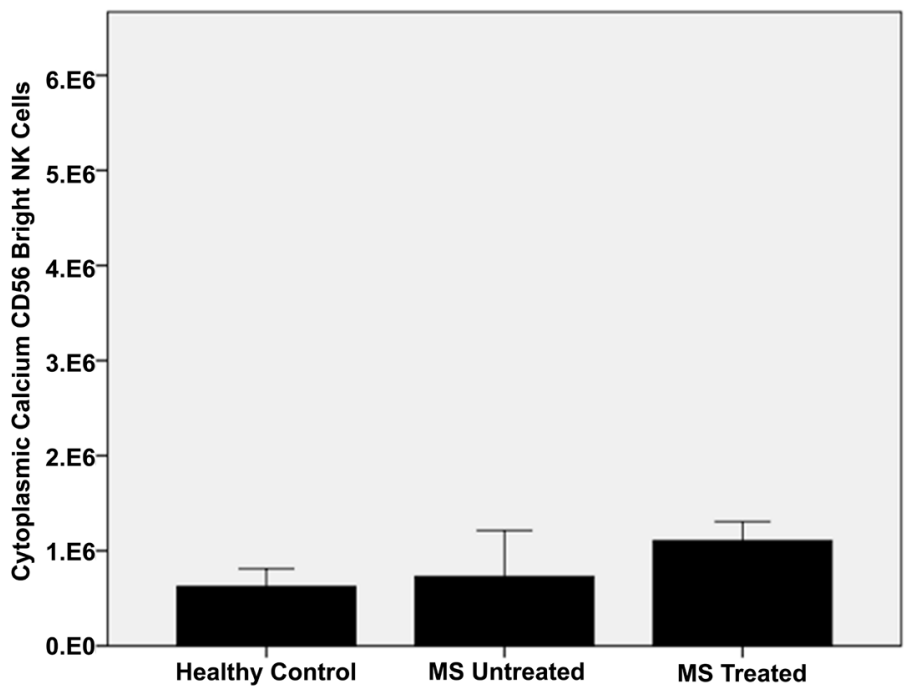

(g)

Figure 5. Cytoplasmic calcium in CD56 ${ }^{\text {Bright }} \mathrm{NK}$ cells. (a) $\mathrm{Ca}^{2+}$ flux response area under the curve-treated 2-ABP; (b) $\mathrm{Ca}^{2+}$ flux response area under the curve-treated Ionomycin. (c) $\mathrm{Ca}^{2+}$ flux response area under the curve-treated PregS; (d) $\mathrm{Ca}^{2+}$ flux response area under the curve-treated PregS + 2-ABP; (e) $\mathrm{Ca}^{2+}$ flux response area under the curve-treated PregS + TG. (f) $\mathrm{Ca}^{2+}$ flux response area under the curve-treated TG. (g) $\mathrm{Ca}^{2+}$ flux response area under the curve-US. Data are represented as mean \pm SEM. Asterisks $\left(^{*}\right)$ represent statistical significance at $p$ value $<0.05$. Abbreviations: US: Unstimulated, PregS: Pregnenolone sulphate, TG: Thapsigargin, 2-ABP: 2-Aminoethoxydiphenyl borate, AUC: area under curve, MS: Multiple sclerosis, NK: natural killer.

showed significant increase in AUC in the treated MS group compared to the untreated MS group when under treatment with TG (Figure 6(b)).

\section{Discussion}

This is the first study to investigate $\mathrm{NK}$ cell $\mathrm{Ca}^{2+}$ mobilisation and surface expression of TRPM3 in MS patients and HC. The current study reports no significant difference in NK cell cytotoxic activity between MS patients and HC. Importantly, variations in TRPM3, CD69 and CD107a expression were reported. Moreover, there was a significant increase in intracellular $\mathrm{Ca}^{2+}$ signalling in $\mathrm{NK}$ cells isolated from treated MS patients compared with untreated patients.

Previous investigations have reported a significant reduction in NK cell cytotoxicity against the human K562 cell line [6] [10] [11] [12] [13], conversely others have reported no difference in NK cell cytotoxic activity between MS patients and HC [43] [44]. The current investigation reported no significant changes in NK cell cytotoxicity in MS patients compared with HC. However, this investigation is limited through its small sample size. A rationale for the outcomes reported in previous investigations may be due to heterogeneity between studies with respect to study design and cohort selection. For example, flow cytometric techniques for measuring cytotoxicity are more sensitive that the chromium (Cr)-51 release assay. In addition, research suggests that NK cell cytotoxic 


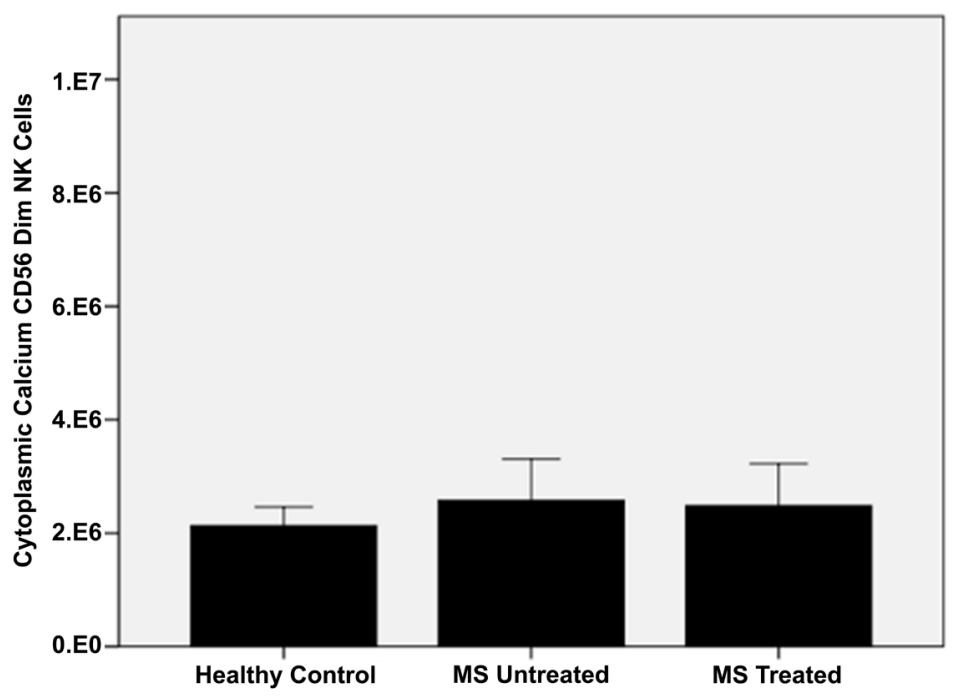

(a)

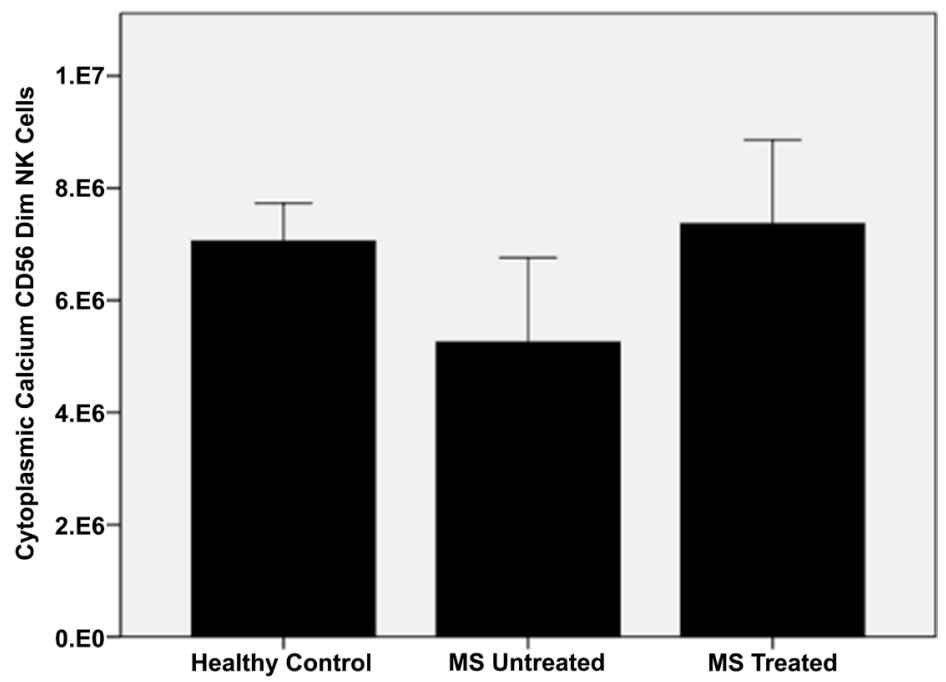

(b)

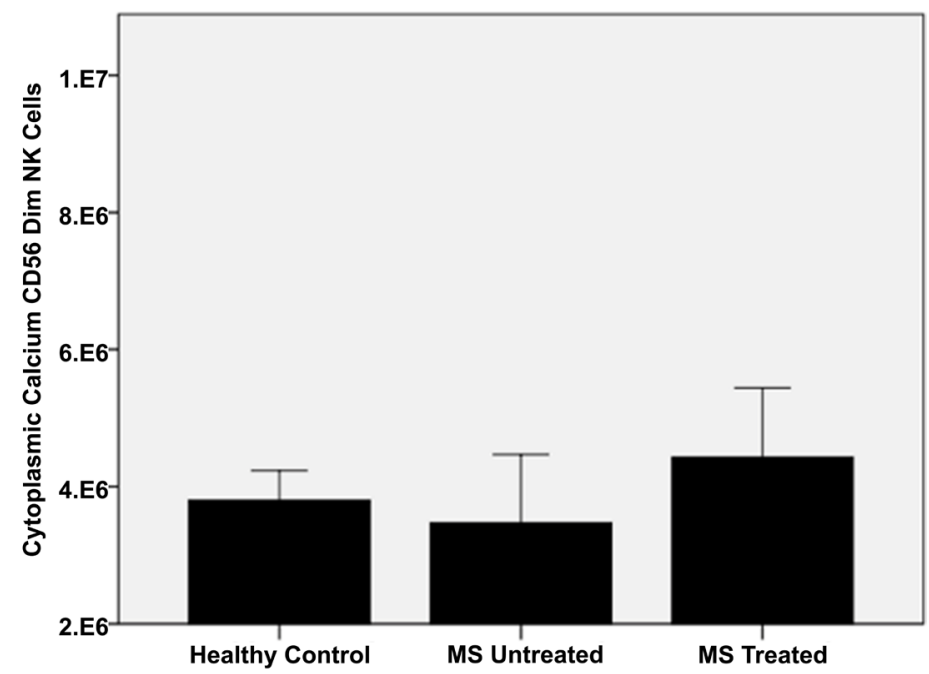

(c) 


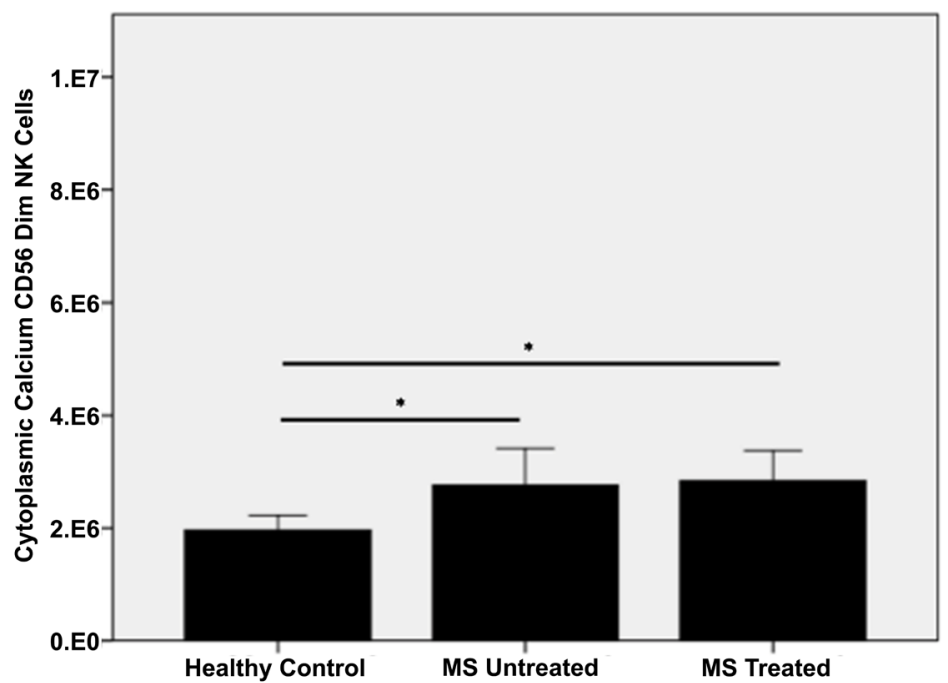

(d)

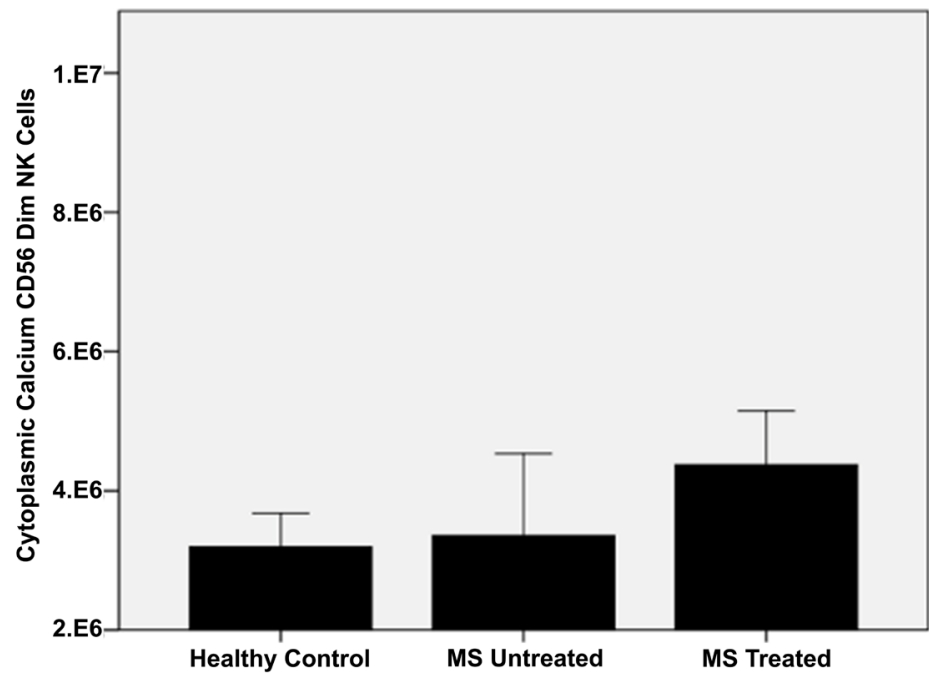

(e)

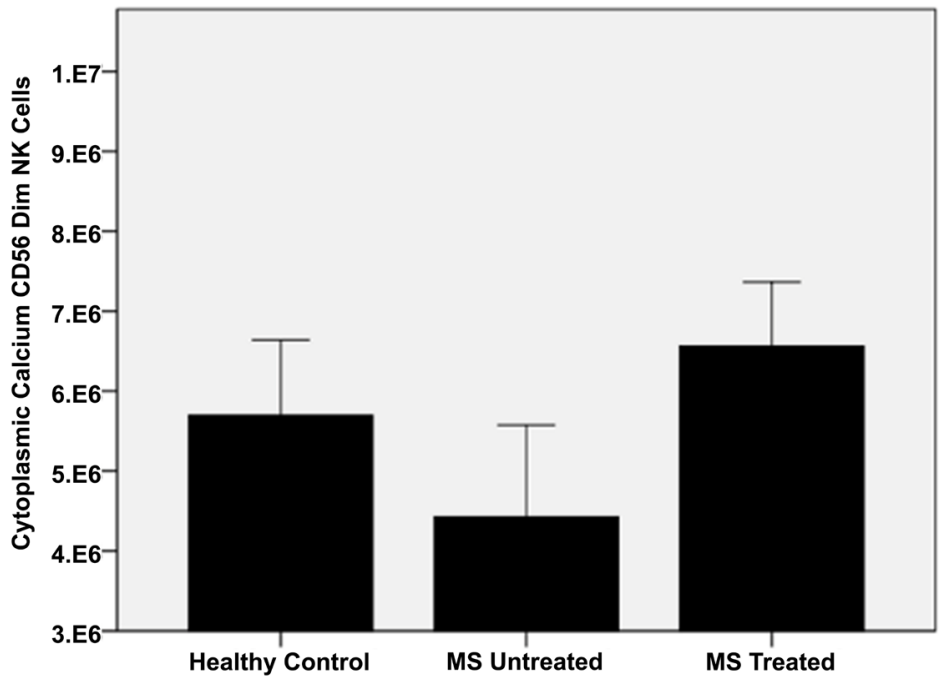

(f) 


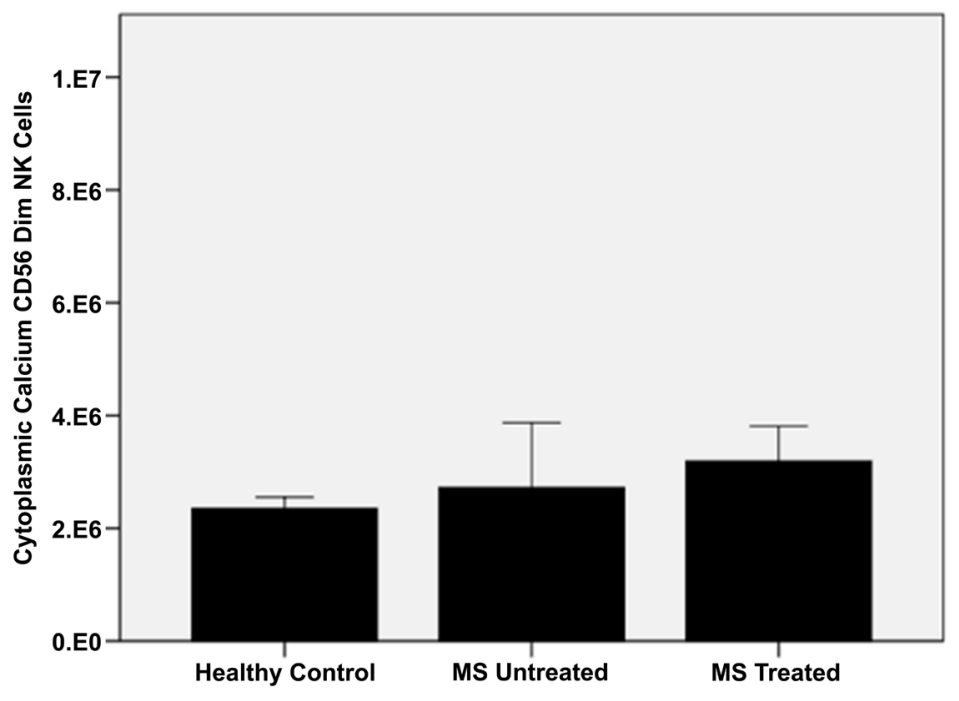

(g)

Figure 6. Cytoplasmic calcium in $\mathrm{CD} 56^{\mathrm{Dim}} \mathrm{NK}$ cells. (a) $\mathrm{Ca}^{2+}$ flux response area under the curve-treated 2-ABP; (b) $\mathrm{Ca}^{2+}$ flux response area under the curve-treated Ionomycin. (c) $\mathrm{Ca}^{2+}$ flux response area under the curve-treated PregS; (d) $\mathrm{Ca}^{2+}$ flux response area under the curve-treated PregS + 2-ABP; (e) $\mathrm{Ca}^{2+}$ flux response area under the curve-treated PregS + TG; (f) $\mathrm{Ca}^{2+}$ flux response area under the curve-treated TG; (g) $\mathrm{Ca}^{2+}$ flux response area under the curve-US. Data are represented as mean \pm SEM. Asterisks $\left.{ }^{*}{ }^{\star}\right)$ represent statistical significance at $p$ value $<0.05$. Abbreviations: US: Unstimulated, PregS: Pregnenolone sulphate, TG: Thapsigargin, 2-ABP: 2-Aminoethoxydiphenyl borate, AUC: area under curve, MS: Multiple sclerosis, NK: natural killer.

activity is dependent on disease activity, as NK cell function is impaired during clinical relapse however normalized during remission. Therefore, our findings may reflect an immune profile of MS patients during remittent phase of disease. It is important to note alemtuzumab is believed to have little to no effect on CD52 expression on NK cells [37]. Hu et al. suggested that due to minimal expression of CD52, NK cells are unaffected by alemtuzumab and can continue carrying on cytotoxicity and production of cytokines [37]. As the mechanism of alemtuzumab may be a result of antibody-dependent cell mediated cytotoxicity future research will investigate CD16 expression on NK cells.

Despite not reporting significant differences in NK cell cytotoxic activity, this current investigation reports a variations in NK cell activation marker CD69 in CD56 ${ }^{\text {Dim }}$ and CD56 $6^{\text {Bright }}$ NK cells. CD69 is implicated in the non-selective early activation of $\mathrm{NK}$ cells resulting in cellular proliferation, secretion and cytotoxic activity [45]. We report that CD69 expression is significantly lower on CD56 ${ }^{\text {Dim }}$ NK cells in untreated MS patients prior to drug stimulation and following stimulation with PregS, PregS + 2-ABP and 2-ABP only. Moreover, CD69 expression is significantly increased in treated MS patients compared with untreated MS patients on CD56 ${ }^{\text {Dim }}$ NK cells.

Whilst this current investigation did not report a concurrent increase in CD69 expression CD56 ${ }^{\text {Bright }} \mathrm{NK}$ cells, there was an upward trend in untreated MS patients compared with HC prior to drug stimulation. The reason for this is un- 
known, however may be attributed to lack of NK cell-dependent immunoregulation of autoreactive T lymphocytes in untreated MS patients. Gross et al. suggests that alemtuzumab administration may promote NK cell efficiency in MS patients [46] possibly explaining alterations in CD69 expression seen in this investigation.

Interestingly, there was a significant increase in CD107a expression on CD56 ${ }^{\text {Bright }}$ NK cells in untreated MS patients compared with HC and patients treated with alemtuzumab. CD107a expression increases with NK cell activation and indirectly correlates with both cytokine secretion and NK cell cytotoxicity [48]. Other investigators have postulated that $\mathrm{T}$ lymphocyte death is mediated by CD56 ${ }^{\text {Bright }} \mathrm{NK}$ cells through the release of pro-inflammatory cytokines [47]. Moreover, this current project suggests that variations in CD56 ${ }^{\mathrm{Dim}} \mathrm{NK}$ cell activation may be implicated in altered NK cell cytotoxic activity in MS patients. Altered NK cell activation and function in MS patients may be dependent on pharmacological stimulant, phase of $\mathrm{NK}$ cell activation (selective vs non-selective), and disease activity (relapsing remitting vs progressive; active vs remission), as evidenced by the different expression of CD69 and CD107a observed in this study.

Moreover, previous literature has examined the role of interferon therapies on NK cell function [11] [12] and the subsequent increase in the percentage of CD56 $6^{\text {Bright }} \mathrm{NK}$ cells suggesting alemtuzumab expands CD56 ${ }^{\text {Bright }} \mathrm{NK}$ cell subset [46] [49]. A previous investigation reported that removal of NK cells inhibited alemtuzumab-induced release of cytokines and cytotoxicity [37], suggesting that treatment of MS patients with alemtuzumab results in altered NK cell profiling to reflect that seen in HC. This finding suggests that an altered NK cell profile may be implicated in the pathophysiological changes in MS, and furthermore suggests that alemtuzumab may mediate therapeutic effect via alteration in NK cell profiling.

We report novel findings as TRPM3 expression was significantly increased on CD56 ${ }^{\text {Dim }} \mathrm{NK}$ cells in untreated MS patients compared with HC following stimulation with PregS. TRPM3 expression in treated MS patients appeared comparable with HC. TRPM3 channels are activated in response to depleted intracellular $\mathrm{Ca}^{2+}$ stores [32] [50] and an increase in TRPM3 expression results in an increase in cytoplasmic $\mathrm{Ca}^{2+}$ levels [32]. In the present investigation, MS patients treated with alemtuzumab that had normalised TRPM3 expression may or may not be associated with $\mathrm{Ca}^{2+}$ influx. As observed in CD56 $6^{\text {Bright }} \mathrm{NK}$ cells where TRPM3 expression was increased in treated MS patients, however, was not significant for CD56 ${ }^{\mathrm{Dim}} \mathrm{NK}$ cells. It is speculated that MS patients may have impaired $\mathrm{Ca}^{2+}$ influx which is compensated by increased surface expression TRPM3. These findings suggest that alemtuzumab may increase $\mathrm{Ca}^{2+}$ influx that potentially alters TRPM3 expression. Currently, there is no literature reporting on the effects of alemtuzumab on TRPM3 channels and $\mathrm{Ca}^{2+}$ mobilisation. Moreover, PregS is a potent and reversible TRPM3 agonist [51], and therefore these results may suggest a role for TRPM3 in the altered NK cell profiling as discussed previously. 
Despite this however, similar changes were not seen in the unstimulated state, or under stimulation with Preg + 2-ABP or PregS + TG. Further studies with a larger cohort would be required to elucidate whether TRPM3 may be implicated in altered NK profiling in MS.

The current investigation demonstrated that under all stimulated conditions except PregS +2-ABP and Ionomycin, there was a significant increase in intracellular $\mathrm{Ca}^{2+}$ signalling in $\mathrm{CD} 56^{\text {Bright }} \mathrm{NK}$ cells of patients treated with alemtuzumab compared with untreated patients. However, there was only a concurrent significant change in intracellular $\mathrm{Ca}^{2+}$ signalling in the $\mathrm{CD}^{2} 6^{\text {Dim }} \mathrm{NK}$ cell population between treated and untreated patients under the treatment with TG alone. Furthermore there was no significant difference in $\mathrm{Ca}^{2+}$ signalling in $\mathrm{CD} 56^{\mathrm{Dim}}$ NK cells between MS subgroups in unstimulated conditions. This study therefore suggests that whilst there may be changes in $\mathrm{Ca}^{2+}$ signalling due to alemtuzumab therapy in NK cells of MS patients, intracellular $\mathrm{Ca}^{2+}$ signalling alone is insufficient to explain the changes in NK cell profiling seen in this study.

The results of this study are limited by the small sample size however, the cohort groups were well matched with no significant differences between groups with respect to age, disease duration, EDSS, and number of relapses. The lower age of onset in the alemtuzumab group is considered to reflect a treatment bias towards patients with this disease modifying therapy in the earlier stages of disease. Similarly, the alemtuzumab group demonstrated a significantly reduced lymphocyte count when compared with HC and untreated MS patients. This may reflect alemtuzumab-dependent elimination of lymphocytes bearing CD52 [33].

\section{Conclusion}

This pilot study supports previous literature in that while the overall cytotoxic function of NK cells in MS patients does not appear impaired, we demonstrate that NK cell profiling is altered in MS patients, with an upregulation of CD56 $6^{\mathrm{Dim}}$ NK cell populations expressing CD69, and that these effects can be abrogated by alemtuzumab therapy. Whilst intracellular $\mathrm{Ca}^{2+}$ signalling does not appear to account for changes in NK cell profiling of MS patients, the present study suggests that intracellular $\mathrm{Ca}^{2+}$ signalling in NK cells may be implicated in the therapeutic effects of alemtuzumab. The role of TRP ion channels such as TRPM3 should be further explored for their role in the pathophysiology and potential treatment of MS.

\section{Acknowledgements}

The authors would like to acknowledge the contribution of Dr Marshall Feterl for laboratory work completed for this project.

\section{Data Availability}

Data sharing is not applicable to this article as no datasets were generated under the Griffith University Intellectual Property policy. Supporting data of this study 
is included within the article.

\section{Ethical Approval}

This study was approved by Griffith University Human Research Ethic Committee (MSC/18/13).

\section{Funding}

This research was supported by funding from the Stafford Fox Medical Research Foundation, Mr Douglas Stutt, Blake Beckett Foundation, Alison Hunter Memorial Foundation and the Queensland Government Co-Investment Program.

\section{Conflicts of Interest}

The authors have reviewed and approved the final version of this manuscript and declare no conflict of interest in the research presented.

\section{Author Contributions}

SMG, DS and SB conceived and designed experiment and provided consumables for this current investigation. LC and TN performed experiments, and participant recruitment. LC, TN and NE performed data analysis. SJ supervised research, data analysis and the writing of this manuscript. LC and NE drafted and constructed the final manuscript.

\section{References}

[1] Gandhi, R., Laroni, A. and Weiner, H.L. (2010) Role of the Innate Immune System in the Pathogenesis of Multiple Sclerosis. Journal of Neuroimmunology, 221, 7-14. https://doi.org/10.1016/j.jneuroim.2009.10.015

[2] Hemmer, B., Kerschensteiner, M. and Korn, T. (2015) Role of the Innate and Adaptive Immune Responses in the Course of Multiple Sclerosis. The Lancet Neurology, 14, 406-419. https://doi.org/10.1016/S1474-4422(14)70305-9

[3] Goldenberg, M.M. (2012) Multiple Sclerosis Review. Pharmacy and Therapeutics, 37, 175-184.

[4] Kingwell, E., et al. (2013) Incidence and Prevalence of Multiple Sclerosis in Europe: A Systematic Review. BMC Neurology, 13, 128.

[5] Segal, B.M. (2007) The Role of Natural Killer Cells in Curbing Neuroinflammation. Journal of Neuroimmunology, 191, 2-7. https://doi.org/10.1016/j.jneuroim.2007.09.006

[6] Benczur, M., et al. (1980) Dysfunction of Natural Killer Cells in Multiple Sclerosis: A Possible Pathogenetic Factor. Clinical and Experimental Immunology, 39, 657-662.

[7] Merrill, J., Jondal, M., Seeley, J., Ullberg, M. and Sidén, A. (1982) Decreased NK Killing in Patients with Multiple Sclerosis: An Analysis on the Level of the Single Effector Cell in Peripheral Blood and Cerebrospinal Fluid in Relation to the Activity of the Disease. Clinical and Experimental Immunology, 47, 419-430.

[8] Duffy, S.S., Lees, J.G. and Moalem-Taylor, G. (2014) The Contribution of Immune and Glial Cell Types in Experimental Autoimmune Encephalomyelitis and Multiple 
Sclerosis. Multiple Sclerosis International, 2014, Article ID: 285245.

[9] Caligiuri, M.A. (2008) Human Natural Killer Cells. Blood, 112, 461-469. https://doi.org/10.1182/blood-2007-09-077438

[10] Vranes, Z., Poljakovic, Z. and Marusic, M. (1989) Natural Killer Cell Number and Activity in Multiple Sclerosis. Journal of the Neurological Sciences, 94, 115-123. https://doi.org/10.1016/0022-510X(89)90222-0

[11] Uchida, A., Maida, E.M., Lenzhofer, R. and Micksche1, M. (1982) Natural Killer Cell Activity in Patients with Multiple Sclerosis: Interferon and Plasmapheresis. Immunobiology, 160, 392-402. https://doi.org/10.1016/S0171-2985(82)80003-X

[12] Hirsch, R.L. and Johnson, K.P. (1985) Natural Killer Cell Activity in Multiple Sclerosis Patients Treated with Recombinant Interferon- $\alpha_{2}$. Clinical Immunology and Immunopathology, 37, 236-244. https://doi.org/10.1016/0090-1229(85)90155-2

[13] Braakman, E., van Tunen, A., Meager, A. and Lucas, C.J. (1986) Natural Cytotoxic Activity in Multiple Sclerosis Patients: Defects in IL-2/Interferon Gamma-Regulatory Circuit. Clinical \& Experimental Immunology, 66, 285-294.

[14] Bielekova, B., et al. (2006) Regulatory CD56 $6^{\text {bright }}$ Natural Killer Cells Mediate Immunomodulatory Effects of IL-2R $\alpha$-Targeted Therapy (Daclizumab) in Multiple Sclerosis. Proceedings of the National Academy of Sciences of the United States of America, 103, 5941-5946. https://doi.org/10.1073/pnas.0601335103

[15] Kastrukoff, L.F., Lau, A., Wee, R., Zecchini, D., White, R. and Paty, D.W. (2003) Clinical Relapses of Multiple Sclerosis Are Associated with "Nove" Valleys in Natural Killer Cell Functional Activity. Journal of Neuroimmunology, 145, 103-114. https://doi.org/10.1016/j.jneuroim.2003.10.001

[16] Feske, S., Wulff, H. and Skolnik, E.Y. (2015) Ion Channels in Innate and Adaptive Immunity. Annual Review of Immunology, 33, 291-353.

https://doi.org/10.1146/annurev-immunol-032414-112212

[17] Schwarz, E.C., Qu, B. and Hoth, M. (2013) Calcium, Cancer and Killing: The Role of Calcium in Killing Cancer Cells by Cytotoxic T Lymphocytes and Natural Killer Cells. Biochimica et BiophysicaActa (BBA)-Molecular Cell Research, 1833, 1603-1611. https://doi.org/10.1016/j.bbamcr.2012.11.016

[18] Nilius, B. and Owsianik, G. (2011) The Transient Receptor Potential Family of Ion Channels. Genome Biology, 12, 218. https://doi.org/10.1186/gb-2011-12-3-218

[19] Nilius, B. and Flockerzi, V. (2014) Mammalian Transient Receptor Potential (TRP) Cation Channels. Vol. 2, Springer, Berlin. https://doi.org/10.1007/978-3-642-54215-2

[20] Fleig, A. and Penner, R. (2004) The TRPM Ion Channel Subfamily: Molecular, Biophysical and Functional Features. Trends in Pharmacological Sciences, 25, 633-639. https://doi.org/10.1016/j.tips.2004.10.004

[21] Moran, M.M., McAlexander, M.A., Bíró, T. and Szallasi, A. (2011) Transient Receptor Potential Channels as Therapeutic Targets. Nature Reviews Drug Discovery, 10, 601-620. https://doi.org/10.1038/nrd3456

[22] Clapham, D.E., Runnels, L.W. and Strübing, C. (2001) The TRP Ion Channel Family. Nature Reviews Neuroscience, 2, 387-396. https://doi.org/10.1038/35077544

[23] Schattling, B., et al. (2012) TRPM4 Cation Channel Mediates Axonal and Neuronal Degeneration in Experimental Autoimmune Encephalomyelitis and Multiple Sclerosis. Nature Medicine, 18, 1805-1811. https://doi.org/10.1038/nm.3015

[24] Paltser, G., et al. (2013) TRPV1 Gates Tissue Access and Sustains Pathogenicity in 
Autoimmune Encephalitis. Molecular Medicine, 19, 149-159. https://doi.org/10.2119/molmed.2012.00329

[25] Grimm, C., Kraft, R., Sauerbruch, S., Schultzand, G. and Harteneck, C. (2003) Molecular and Functional Characterization of the Melastatin-Related Cation Channel TRPM3. Journal of Biological Chemistry, 278, 21493-21501. https://doi.org/10.1074/jbc.M300945200

[26] Papanikolaou, M., Lewis, A. and Butt, A. (2017) Store-Operated Calcium Entry Is Essential for Glial Calcium Signalling in CNS White Matter. Brain Structure and Function, 222, 2993-3005. https://doi.org/10.1007/s00429-017-1380-8

[27] Vriens, J., et al. (2011) TRPM3 Is a Nociceptor Channel Involved in the Detection of Noxious Heat. Neuron, 70, 482-494. https://doi.org/10.1016/j.neuron.2011.02.051

[28] Oberwinkler, J. and Philipp, S. (2007) TRPM3. In: Flockerzi, V. and Nilius, B., Eds., Transient Receptor Potential (TRP) Channels, Springer, Berlin, 253-267. https://doi.org/10.1007/978-3-540-34891-7_15

[29] Nguyen, T., Staines, D., Nilius, B., Smith, P. and Marshall-Gradisnik, S. (2016) Novel Identification and Characterisation of Transient Receptor Potential Melastatin 3 Ion Channels on Natural Killer Cells and B Lymphocytes: Effects on Cell Signalling in Chronic Fatigue Syndrome/Myalgic Encephalomyelitis Patients. Biological Research, 49, 27. https://doi.org/10.1186/s40659-016-0087-2

[30] Zierler, S., Hampe, S. and Nadolni, W. (2017) TRPM Channels as Potential Therapeutic Targets against Pro-Inflammatory Diseases. Cell Calcium, 67, 105-115. https://doi.org/10.1016/j.ceca.2017.05.002

[31] Launay, P., et al. (2004) TRPM4 Regulates Calcium Oscillations after T Cell Activation. Science, 306, 1374-1377. https://doi.org/10.1126/science.1098845

[32] Nguyen, T., Johnston, S., Clarke, L., Smith, P. Staines, D. and Marshall - Gradisnik, S. (2017) Impaired Calcium Mobilization in Natural Killer Cells from Chronic Fatigue Syndrome/Myalgic Encephalomyelitis Patients Is Associated with Transient Receptor Potential Melastatin 3 Ion Channels. Clinical \& Experimental Immunology, 187, 284-293. https://doi.org/10.1111/cei.12882

[33] Willis, M.D. and Robertson, N.P. (2016) Alemtuzumab for Multiple Sclerosis. Current Neurology and Neuroscience Reports, 16, 84. https://doi.org/10.1007/s11910-016-0685-y

[34] Jiang, L., et al. (2009) Variable CD52 Expression in Mature T Cell and NK Cell Malignancies: Implications for Alemtuzumab Therapy. British Journal of Haematology, 145, 173-179. https://doi.org/10.1111/j.1365-2141.2009.07606.x

[35] Moreau, T., et al. (1994) Preliminary Evidence from Magnetic Resonance Imaging for Reduction in Disease Activity after Lymphocyte Depletion in Multiple Sclerosis. The Lancet, 344, 298-301. https://doi.org/10.1016/S0140-6736(94)91339-0

[36] Coles, A.J., et al. (1999) Monoclonal Antibody Treatment Exposes Three Mechanisms Underlying the Clinical Course of Multiple Sclerosis. Annals of Neurology, 46, 296-304. https://doi.org/10.1002/1531-8249(199909)46:3<296::AID-ANA4>3.0.CO;2-\#

[37] Hu, Y., Turner, M.J., Shields J., et al. (2009) Investigation of the Mechanism of Action of Alemtuzumab in a Human CD52 Transgenic Mouse Model. Immunology, 128, 260-270. https://doi.org/10.1111/j.1365-2567.2009.03115.x

[38] Polman, C.H., et al. (2011) Diagnostic Criteria for Multiple Sclerosis: 2010 Revisions to the McDonald Criteria. Annals of Neurology, 69, 292-302. 
https://doi.org/10.1002/ana.22366

[39] Wagner, T.F., et al. (2008) Transient Receptor Potential M3 Channels Are Ionotropic Steroid Receptors in Pancreatic $\beta$ Cells. Nature Cell Biology, 10, 1421-1430. https://doi.org/10.1038/ncb1801

[40] Lytton, J., Westlin, M. and Hanley, M.R. (1991) Thapsigargin Inhibits the Sarcoplasmic or Endoplasmic Reticulum Ca-ATPase Family of Calcium Pumps. Journal of Biological Chemistry, 266, 17067-17071.

[41] Huth, T., Brenu E.W., Ramos, S., et al. (2016) Pilot Study of Natural Killer Cells in Chronic Fatigue Syndrome/Myalgic Encephalomyelitis and Multiple Sclerosis. Scandinavian Journal of Immunology, 83, 44-51. https://doi.org/10.1111/sji.12388

[42] Aubry, J.P., et al. (1999) Annexin V Used for Measuring Apoptosis in the Early Events of Cellular Cytotoxicity. Cytometry, 37, 197-204.

https://doi.org/10.1002/(SICI)1097-0320(19991101)37:3<197::AID-CYTO6>3.0.CO; $\underline{2-\mathrm{L}}$

[43] Rice, G.P.A., Casali, P., Merigan, T.C. and Oldstone, M.B.A. (1983) Natural Killer Cell Activity in Patients with Multiple Sclerosis Given $\alpha$ Interferon. Annals of Neurology, 14, 333-338. https://doi.org/10.1002/ana.410140312

[44] Santoli, D., et al. (1981) Cytotoxic Activity and Interferon Production by Lymphocytes from Patients with Multiple Sclerosis. Journal of Immunology, 126, 1274-1278.

[45] Moretta, A., et al. (1991) CD69-Mediated Pathway of Lymphocyte Activation: Anti-CD69 Monoclonal Antibodies Trigger the Cytolytic Activity of Different Lymphoid Effector Cells with the Exception of Cytolytic T Lymphocytes Expressing T Cell Receptor Alpha/Beta. Journal of Experimental Medicine, 174, 1393-1398. https://doi.org/10.1084/jem.174.6.1393

[46] Gross, C.C., et al. (2016) Alemtuzumab Treatment Alters Circulating Innate Immune Cells in Multiple Sclerosis. Neurology-Neuroimmunology \& Neuroinflammation, 3, e289. https://doi.org/10.1212/NXI.0000000000000289

[47] Laroni, A., et al. (2016) Dysregulation of Regulatory CD56 $6^{\text {bright }}$ NK Cells/T Cells Interactions in Multiple Sclerosis. Journal of Autoimmunity, 72, 8-18.

https://doi.org/10.1016/j.jaut.2016.04.003

[48] Alter, G., Malenfant, J.M. and Altfeld, M. (2004) CD107a as a Functional Marker for the Identification of Natural Killer Cell Activity. Journal of Immunological Methods, 294, 15-22. https://doi.org/10.1016/j.jim.2004.08.008

[49] Saraste, M., Irjala, H. and Airas, L. (2007) Expansion of CD56 ${ }^{\text {Bright }}$ Natural Killer Cells in the Peripheral Blood of Multiple Sclerosis Patients Treated with Interferon- $\beta$. Neurological Sciences, 28, 121-126.

https://doi.org/10.1007/s10072-007-0803-3

[50] Lee, N., et al. (2003) Expression and Characterization of Human Transient Receptor Potential Melastatin 3 (hTRPM3). Journal of Biological Chemistry, 278, 20890-20897. https://doi.org/10.1074/jbc.M211232200

[51] Harteneck, C. (2013) Pregnenolone Sulfate: From Steroid Metabolite to TRP Channel Ligand. Molecules, 18, 12012-12028.

https://doi.org/10.3390/molecules 181012012 


\section{Supplementary Material}
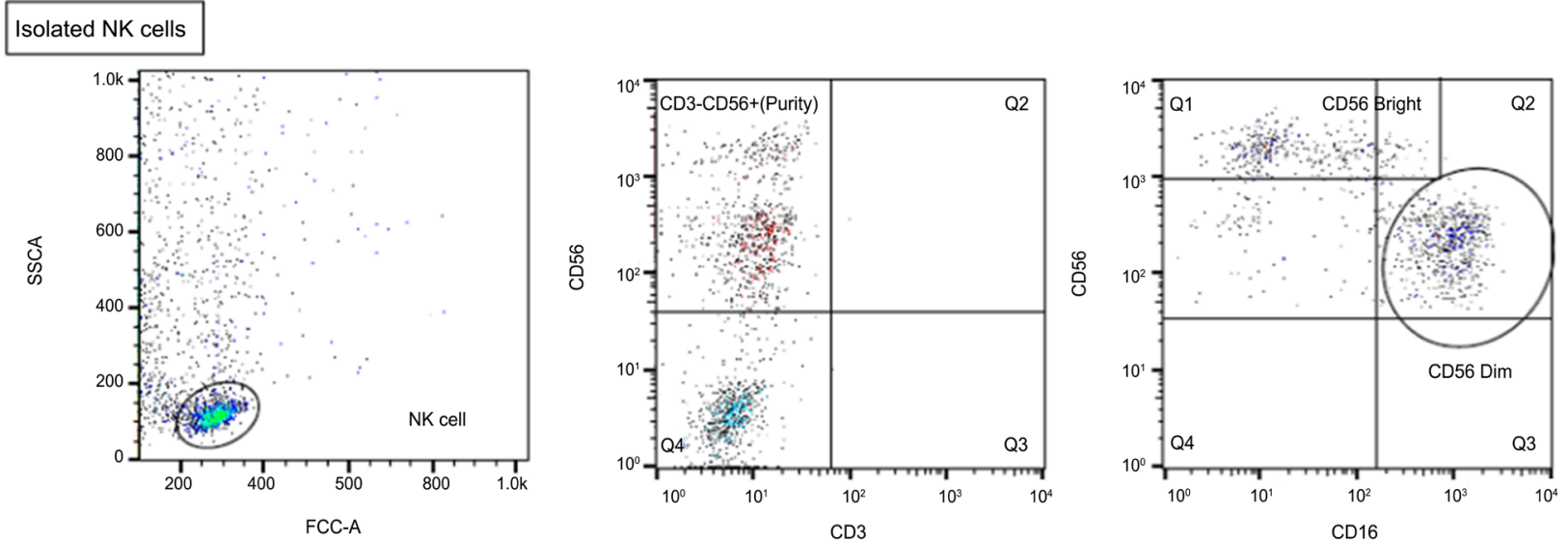

CD56 Dim NK cells
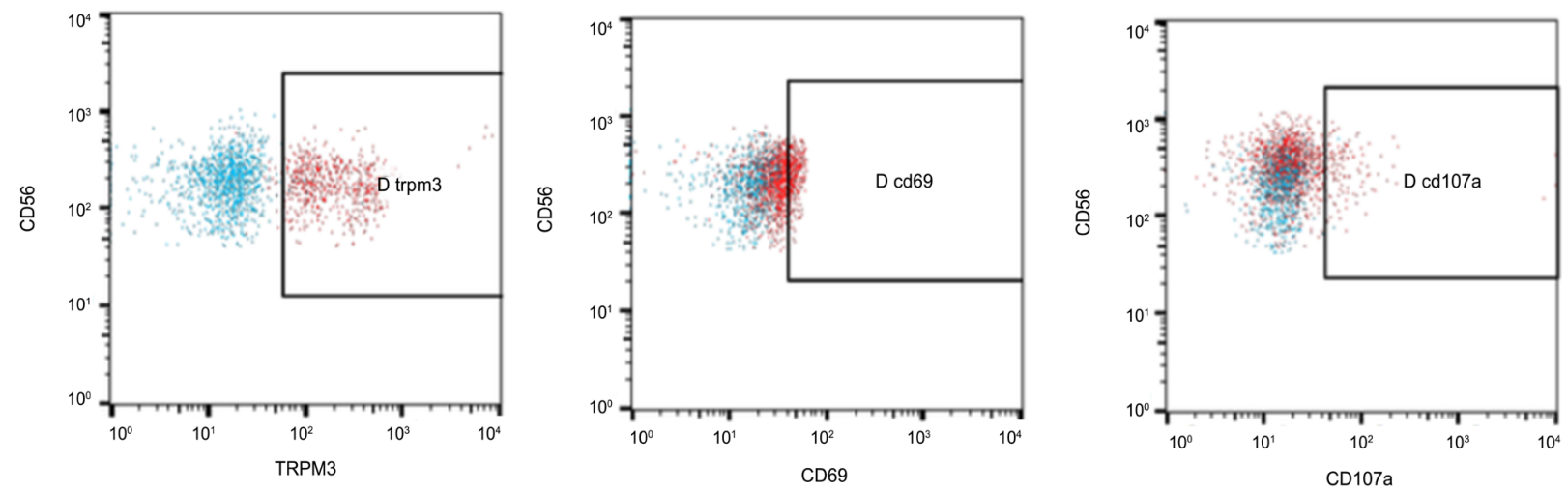

Supplementary Figure 1. Flow cytometric gating for TRPM3, CD69 and CD107a. Natural killer (NK) cells were gated $\left(\mathrm{CD} 56^{+} \mathrm{CD}^{-}\right)$. NK cell subsets, such as $\mathrm{CD} 56^{\text {Dim }}$ and $\mathrm{CD} 56^{\text {Bright }}$ were gated using CD56 and CD16 antibodies. To determine TRPM3, CD69 and CD107a surface expression. Surface antibody staining was used and cells were gated on either CD56 ${ }^{\text {Bright }}$ or $\mathrm{CD} 56^{\text {Dim }}$ to differentiate subsets. Isotype controls were used to determine positive population.

Supplementary Table 1. Clinical and demographic data. Data shown indicates mean, SD, percentage values and p-values as indicated. Significant p-values highlighted in bold text. HC: healthy control MS: Multiple sclerosis, EDSS: expanded disability status scale, CIS: clinically isolated syndrome, RR: Relapsing remitting MS, PP: Primary progressive MS, SP: Secondary progressive MS.

\begin{tabular}{|c|c|c|c|c|c|c|c|c|}
\hline Clinical Feature & $\mathrm{HC}$ & MS & MS-Untreated & $\begin{array}{c}p \text {-value } \\
\text { Untreated } \\
\text { vs HC }\end{array}$ & $\begin{array}{c}\text { MS-Treated } \\
\text { Alemtuzumab }\end{array}$ & $\begin{array}{c}p \text {-value } \\
\text { treated vs HC }\end{array}$ & $\begin{array}{c}p \text {-value } \\
\text { untreated vs } \\
\text { treated }\end{array}$ & $\begin{array}{c}p \text {-value } \\
\text { Chi squared }\end{array}$ \\
\hline $\mathrm{N}$ & 22 & 22 & 12 & - & 10 & - & - & - \\
\hline Age (years) - mean $\pm S D$ & $39.4 \pm 12.5$ & $41.1 \pm 15.2$ & $46.5 \pm 17.0$ & 0.444 & $34.7 \pm 10.0$ & 1.0 & 0.138 & - \\
\hline Gender (female) $-\mathrm{N}(\%)$ & $6(73)$ & $17(77)$ & $8(67)$ & - & $9(90)$ & - & - & \multirow{5}{*}{0.426} \\
\hline Gender (male) $-\mathrm{N}(\%)$ & $16(27)$ & $5(23)$ & $4(33)$ & - & $1(10)$ & - & - & \\
\hline $\begin{array}{c}\text { Age onset (years) - } \\
\text { mean } \pm \mathrm{SD}\end{array}$ & - & $32.6 \pm 10.7$ & $37.2 \pm 10.1$ & - & $27.2 \pm 9.2$ & - & 0.004 & \\
\hline EDSS-mean $\pm S D$ & - & $2.4 \pm 2.6$ & $1.8 \pm 2.3$ & - & $3 \pm 2.9$ & - & 0.434 & \\
\hline $\begin{array}{l}\text { Total number of } \\
\text { relapses-mean } \pm \text { SD }\end{array}$ & - & $3.4 \pm 2.7$ & $3.4 \pm 3.3$ & - & $3.3 \pm 1.9$ & - & 0.833 & \\
\hline
\end{tabular}




\section{Continued}

\begin{tabular}{|c|c|c|c|c|c|c|c|c|}
\hline \multicolumn{9}{|c|}{ Disease course $-\mathrm{N}(\%)$} \\
\hline CIS & - & $4(18)$ & $3(25)$ & - & $1(10)$ & - & - & \\
\hline $\mathrm{RR}$ & - & $17(77)$ & $8(67)$ & - & $9(90)$ & - & - & 0.388 \\
\hline SP & - & $0(0)$ & $0(0)$ & - & $0(0)$ & - & - & \\
\hline PP & - & $1(5)$ & $1(8)$ & - & $0(0)$ & - & - & \\
\hline
\end{tabular}

